\title{
The effect of lightweighting in automotive LCA perspective: estimation of mass- induced fuel consumption reduction for gasoline turbocharged vehicles
}

\author{
Francesco Del Pero, Massimo Delogu, Marco Pierini \\ Department of Industrial Engineering, University of Florence, Italy
}

\begin{abstract}
The paper proposes a method aimed to support Life Cycle Assessment (LCA) in the evaluation of environmental benefits achievable by lightweight design solutions in the automotive field. The study is based on an in-depth calculation of car weight-induced Fuel Consumption (FC) resulting in the Fuel Reduction Value (FRV) coefficient; this is functional in modelling the use stage in a LCA perspective. The research is focused on Gasoline Turbocharged (GT) cars, since to date there is no systematic analysis of weight-induced FC reduction regarding this propulsion technology. The FRV is evaluated for a wide range of vehicle case studies representative of different classes within the 2015 European market. The assessment is performed concentrating on four standardized driving cycles in order to evaluate various driving styles both in the case of primary mass reduction only and in the case of secondary effect (powertrain adaptation in order to maintain vehicle's performance). For the vehicle case studies under consideration, FRV is within the range $0.159-0.237$ and $0.252-0.4771 / 100 \mathrm{~km} * 100 \mathrm{~kg}$ respectively for mass reduction only and secondary effect. Starting from the data obtained, a criterion is refined for estimating the FRV coefficient based on car technical features. Such a method allows to estimate FC reduction precisely by means of the value of FRV closest to the specific application, and it is proposed as a valuable tool for LCA practitioners within the automotive lightweight context.
\end{abstract}

\section{Keywords}

Automotive, Fuel Consumption (FC), Fuel Reduction Value (FRV), Life Cycle Assessment (LCA), lightweighting, mass-induced FC.

\section{Introduction}

Among various economic sectors, transportation contributes significantly to several environmental burdens such as Green-House-Gas (GHG) emissions and resource exploitation (European Commission, 2012): currently transport represents the second largest contributor to anthropogenic GHG emissions within the European Union (Del Pero et al., 2015) and about $20 \%$ of these emissions are generated by road transportation. Considering the automotive Internal Combustion Engine (ICE) context, environmental impact is encountered throughout the vehicle's entire Life Cycle (LC) (Grujicic et al., 2009) and the use stage is responsible for a relevant quota of the total LC impact (Siskos et al., 2015). Such a quota depends on the impact category: with regard to Global Warming Potential (GWP), about $85 \%$ of the overall LC impact is attributable to operation (Koffler, 2013). The use stage impact of a car depends directly on the quantity of fuel consumed (Nemry et al., 2008). Fuel Consumption (FC) is strongly influenced by vehicle weight: about one third of total consumption directly depends on its mass (Rodhe-Brandenburger and Obernolte, 2008). As a consequence, lightweight design has been unanimously recognized as one of the key measures for reducing FC, along with powertrain efficiency, aerodynamics and electrical power management (Kim and Wallington, 2013a). Lightweighting allows the lowering of use stage environmental impact by the reduction of operation consumption (Kelly et al., 2015), but it usually involves contrasting effects on production and End-of-Life (EoL) stages (Dhingra and Das, 2014); therefore a balance should be made between the benefits and disadvantages during the vehicle's whole LC (Geyer, 2008). The comparative Life Cycle Assessment (LCA) is aimed to verify the environmental convenience of innovative lightweight materials, technologies and solutions in replacement of traditional ones. This is a typology of study that has had great diffusion in recent periods and the existing literature provides several case studies referring to the most diverse typologies of automotive lightweight design solutions:

- introduction of weight-efficient materials in substitution of traditional ones: magnesium (Hakamada et al., 2007), bio-based materials (La Rosa et al., 2014), composites reinforced by natural fibres such as jute (Alves et al., 2010), sugarcane bagasse (Luz et al., 2010), curauà (Zah et al., 2006) and cotton (Pegoretti et al., 2014), polymeric composites (Mayyas et al., 2013), hybrid-sandwich materials (Schonemann et al., 2016);

- optimization and novel use of manufacturing technologies and processes: Advanced Sheet Compression Molding (ASCM) applied to fiberglass reinforced plastic thermoset (Dattilo et al., 2017), injection molding used for hollow glass microspheres-reinforced polypropylene (Delogu et al., 2016), reaction injection molding (Simoes et al., 2016), Resin Transfer Molding (RTM), innovative continuous fiber placement process applied to biocomposites (Zanchi et al., 2016);

- redesign and optimization of vehicle components/assemblies: body-in-white (Mayyas et al., 2012a), floor section (Inti et al., 2016), closures (Puri et al., 2009), exterior body panels (Poulikidou et al., 2016), interiors (Koffler and Zahller 2012), engine compartment parts (Delogu et al., 2015). 
Literature review reveals that, opposite to operation impact reduction, innovative lightweight design normally entails higher energy consumption and $\mathrm{CO}_{2}$ emissions for production and EoL stages (Vinodh and Jayakrishna, 2011). This yields break-even mileages, i.e. the total driving distance required to compensate the production and EoL emissions through reduced FC during operation (Raugei et al., 2015); a critical issue here is the prediction of the LC mileage, as the decision for innovative design solutions depends strictly on the position of the breakeven point within a vehicle's lifetime (Weymar and Finkbeiner, 2015).

In the light of the previous considerations, it can be stated that when dealing with one or more lightweight design solutions, it is essential to accurately assess the potentiality of lowering the use stage impact through an accurate estimation of the mass-induced FC reduction.

\section{Use stage in comparative LCA of ICE vehicles}

The most widespread instrument for evaluating the environmental impact of products or services is the LCA methodology. LCA has been employed largely in the transportation sector (Mayyas et al., 2012b); considering the automotive lightweight context, many examples of comparative LCAs already exist (Baroth et al., 2012) and the interest in this field is continually growing. Literature provides two main approaches for the treatment of the use stage within the automotive lightweight LCA context: Proportions-based and FRV-based. Both methods are founded on an estimation of the FC saving achievable through mass reduction. Below a description of such approaches is reported, also including a review of LCA case studies from literature.

Proportions-based approach. The proportions-based approach is founded on the assumption of a linear dependence between the quota of

- FC saving with respect to total vehicle FC

- mass saving with respect to total vehicle mass

through a proportionality constant (Eq. 1).

$\frac{\Delta F C}{\Delta M}=\frac{F C_{\text {ref_veh }}}{M_{\text {ref_veh }}} * C$

Where:

$\triangle F C=$ Fuel Consumption reduction achieved through vehicle mass reduction $[1 / 100 \mathrm{~km}]$;

$\Delta M=$ vehicle Mass reduction $[\mathrm{kg}]$;

$F C_{\text {ref_veh }}=$ Fuel Consumption of reference vehicle $[1 / 100 \mathrm{~km}]$

$M_{\text {ref_veh }}=$ Mass of reference vehicle $[\mathrm{kg}]$;

$c=$ proportionality constant.

The approach requires a proportionality constant fixed a priori; many existing comparative LCAs adopt the value 0.6 , as suggested by Lynne Ridge (1997). Since such studies deal with cars belonging to different classes that differ significantly in terms of mass, engine, aerodynamic profile and power to mass ratio, the adoption of the same value for the proportionality constant is a point open to criticism: adopting the same $c$ means that the ratio $\frac{\Delta F C / F C_{\text {ref_veh }}}{\Delta M / M_{\text {ref_ceh }}}$ remains unaltered ignoring vehicle technical features of each specific application and this leads to a high level of uncertainty. Considering real case studies, some examples of comparative automotive LCAs that use the proportions-based approach are Ribeiro et al. (2007), Subic and Schiavone (2006) and Witik et al. (2011).

FRV-based approach. In the FRV-based approach FC reduction achievable through lightweighting is determined by the following relation:

$\Delta F C=\Delta M * F R V * 0.01$

Eq. 2

Where:

$\triangle F C=$ Fuel Consumption reduction achieved through mass reduction $[1 / 100 \mathrm{~km}]$;

$\Delta M=$ vehicle Mass reduction $[\mathrm{kg}]$;

$F R V=$ Fuel Reduction Value coefficient $[1 / 100 \mathrm{~km} * 100 \mathrm{~kg}]$.

The FRV coefficient quantifies the FC saving brought by a $100 \mathrm{~kg}$ mass reduction. Unlike proportions-based approach, the FRV-based approach is not founded on a rigid proportionality between car mass and FC; on the contrary, the consumption saving is determined through the FRV, an intensive quantity that can be customized for each specific vehicle model and driving style. Such a possibility allows to obtain more accurate estimation of FC reduction, making the FRV-based approach preferable to the proportions-based one. Current LCA practices supply a range of $0.02-1.00$ 
$[1 / 100 \mathrm{~km} * 100 \mathrm{~kg}]$ for the FRV; in this regard Table I in Supporting Information (SI) appendix reports values adopted by existing lightweight LCAs. The values of FRV come from other studies that deal with the modelling of mass-induced FC reduction; a review of such a typology of studies is reported below.

Some authors consider the reduction of FC as a function of vehicle mass by applying regression curves to data of different vehicles (Rechs et al. (1995) and Schäper (1996, 1997a,b) use a linear correlation, Aichinger (1995) opts for an exponential curve) and determine the FRV as the slope of consumption in function of mass. Assuming a linear relation, the FRV is independent of the observed mass while with an exponential function it depends on the mass value and, for heavy cars, higher consumption reductions are given than for the smaller ones. Both types of correlations seem to be inappropriate for deriving a reasonable value for the FRV, since they do not take into account the numerous factors that characterize a vehicle (such as engine concept, gear ratios, aerodynamics, tires, performance, etc) and that strongly vary from one car to another. Several studies investigate the relationship between energy consumption and mass for different powertrain technologies: ICE (Pagerit et al., 2006), electric (Redelbach et al., 2012), hybrid (Casadei and Broda, 2008), fuel cells (Wohlecker et al., 2007). Eberle and Franze (1998), Koffler and Branderburger (2010), Kim and Wallington (2013b) and Kim et al. (2015) are the main works that:

- deal with calculation of weight-induced FC in lightweight LCA of ICE vehicles;

- perform calculation investigating the theoretical background and underlying physical correlations in order to describe resulting factors and their different applications;

- point out some notable particularities that need to be taken into account when conducting a comparative study.

Eberle and Franze (1998) derives an analytical approach in order to calculate FC and FRV for the entire BMW's 1998 model range. Calculation is performed through the simulation program FALKE. As reference for the profile of gear ratio and vehicle speed the New European Driving Cycle (NEDC) is used (Barlow et al., 2009); two other cycles ("Consumption optimized" and "Sporting") are taken into account in order to perform sensibility analysis based on driving behavior. The authors calculate FC for different values of car weight and determine the FRV as the slope of regression line of consumption in function of mass. The FRV is determined for both Primary Mass Reduction only (PMR) and implementation of Secondary Effects (SE); SE are powertrain adjustments that allow achieving a further reduction of consumption over and above the primary weight-saving effect while maintaining vehicle performance (Table 1). The analysis leads to the following conclusions:

- the FRV obtained for the "Consumption optimized" driving cycle is generally slightly lower with respect to the NEDC while for the "Sporting" driving cycle it is notably greater;

- the FRV in case of SE is definitely higher with respect to PMR;

- mass and FC are connected by a linear relationship, so that saving in consumption is not dependent on the absolute car weight;

- no dependency of reduced FC on the absolute vehicle weight, its power or the specific power-to-weight ratio is established for both Gasoline Naturally Aspirated (GNA) and Diesel Turbocharged (DT) vehicles.

\begin{tabular}{|c|c|c|c|c|}
\hline & \multicolumn{4}{|c|}{ Fuel Reduction Value $[\mathrm{l} / 100 \mathrm{~km} * 100 \mathrm{~kg}]$} \\
\hline & \multicolumn{2}{|c|}{ GNA cars } & \multicolumn{2}{|c|}{ DT cars } \\
\hline & PMR & SE & PMR & SE \\
\hline NEDC & $0.073-0.139$ & $0.363-0.447$ & $0.118-0.138$ & $0.290-0.330$ \\
\hline Consumption optimized & $0.084-0.145$ & $0.349-0.441$ & $0.120-0.139$ & $0.301-0.368$ \\
\hline Sporting & $0.162-0.235$ & $0.446-0.579$ & $0.165-0.180$ & $0.428-0.457$ \\
\hline
\end{tabular}

Table 1. Fuel Reduction Value [1/100km*100kg] obtained by Eberle and Franze (1998)

Koffler and Branderburger (2010) calculates the FRV for both PMR and SE. In case of PMR, the approach is purely analytical and the FRV is determined in the NEDC as the energy consumed in order to move $100 \mathrm{~kg}$ on a distance of $100 \mathrm{~km}$. The mass-induced FC in the NEDC calculates to 0.15 and $0.121 / 100 \mathrm{~km} * 100 \mathrm{~kg}$ respectively for GNA and DT cars. For the calculation of FRV in case of SE, the authors use mathematical models implemented in a simulation program which takes into account vehicle driving resistances, engine efficiency, transmission ratios, and efficiency of gear/rear axle. FC is determined for various car mass-configurations and the FRV is obtained as the slope of the regression line of consumption in function of mass. Two typologies of SE are implemented: adjustment of gear ratio in order that elasticity $80-120 \mathrm{~km} / \mathrm{h}$ in the top gear remains constant and adaptation of engine displacement in order to maintain the $0-100 \mathrm{~km} / \mathrm{h}$ acceleration. Simulations are carried out for both gasoline and diesel vehicle models belonging to A and B classes in the NEDC. The FRVs obtained in case of SE are reported below: 
- $0.29-0.39 \mathrm{l} / 100 \mathrm{~km} * 100 \mathrm{~kg}$ (gear ratio adjustment) and $0.36-0.451 / 100 \mathrm{~km} * 100 \mathrm{~kg}$ (displacement adaptation) for gasoline vehicles;

- $0.27-0.301 / 100 \mathrm{~km} * 100 \mathrm{~kg}$ (gear ratio adjustment) and $0.24-0.291 / 100 \mathrm{~km} * 100 \mathrm{~kg}$ (displacement adaptation) for diesel vehicles.

Koffler and Branderburger (2010) leads to the following conclusions:

- according to Eberle and Franze (1998) the FRV in case of SE is definitely higher with respect to the case of PMR;

- the FRV in case of SE is calculated through simulation modelling referring to a specific vehicle; as simulations are performed for different car models in terms of size, weight, engine displacement and transmission ratios, only one area can be defined. For this reason the authors conclude that, for a more precise statement, simulations based on technical features (engine full characteristic and gear ratios) of the specific car model should be performed.

Kim and Wallington (2013b) refines a method which determines mass-induced FC based on analytical modelling of car resistance factors. The model provides the mass-induced FC for both PMR and SE; in case of SE powertrain adjustment is applied in order to match the reduced vehicle weight for performance equivalence with respect to the baseline car. The authors illustrate the utility of the method by determining the mass-induced FC for 2013 model year ICE vehicles using the United States Environmental Protection Agency's fuel economy certification data; figures from a homogeneous cohort of 106 cars with automatic transmissions and GNA engines are assumed. The application reveals that lightweighting is shown to have the most benefit when applied to vehicles with high FC and power while vehicle mass does not have strong correlation with mass-induced FC.

Kim et al. (2015) is a work built up on Kim and Wallington (2013b) that shows how use stage FC can be estimated using mass-induced FC in LCAs of vehicle lightweighting. The authors illustrate the utility of mass-induced FC model by estimating LC Green-House-Gas (GHG) emission benefits from lightweighting a grille opening reinforcement component using magnesium or carbon fiber composite for 83 different car models.

From State-of-the-Art (SoA) regarding FRV-based approach studies, the following key findings emerge:

- Application field. Although the naturally aspirated engine family has been widely investigated in the past, for the turbocharged engine family large margins of examination still exist, especially for gasoline vehicles;

- Vehicle range. As researches are based on simulation modelling of a restricted number of car case studies, the resulting FRVs depend on the technical features of the vehicles considered without really being representative of the entire class or engine technology they belong to. Moreover, current studies are focused on single car segments and a systematic analysis investigating a wide range of classes with respect to current vehicle models does not exist;

- Temporal representativeness of FRV values. Some of the existing studies are dated. Considering that vehicle's technical features change over the years and fuel economy of new cars is better with respect to old ones, the FRVs obtained 10-15 years ago for a specific vehicle class nowadays are, nowadays no longer very representative. Additionally, European studies are based on the NEDC driving cycle which is destined to become obsolete in the near future, as the new Worldwide harmonized Light Test Procedure (WLTP) will define a global harmonized standard for Europe within 2017 (Mock et al., 2014; Tutuianu et al., 2013);

- Driving cycle. The studies determine the FRV based on the standardized driving cycles effective in the geographical area of the research. On one hand considering only one cycle involves a significant limitation since no ulterior driving patterns are evaluated; on the other hand the comparability of FRVs is low since driving cycles adopted for calculation differ from one study to the next;

- Availability of vehicle technical parameters. Although literature provides accurate models for calculating FRV (Kim and Wallington, 2013a; Kim et al., 2015), specific vehicle technical parameters, not always available to LCA practitioners, are required for their application.

The aim of this paper is to provide support to LCA practitioners in the evaluation of the environmental benefits achievable through lightweight design solutions within the European automotive context. The study proposes a simplified calculation procedure for mass-induced fuel savings based on the FRV coefficient functional in modelling the use stage in the LCA perspective. The research is founded on an in-depth calculation of car weight-induced FC which attempts to fill the gaps of existing literature:

- the analysis is performed for Gasoline Turbocharged (GT) cars;

- the FRV is estimated for a large number of vehicle case studies belonging to $\mathrm{A} / \mathrm{B}, \mathrm{C}$ and $\mathrm{D}$ classes; within each class of cars, a wide range of technical features (mass, maximum power, power to mass ratio, engine displacement, aerodynamic profile, specific FC, etc) is taken into account; 
- vehicle case studies are representative of the 2015 European car market;

- the FRV is evaluated based on the most globally widespread driving cycles;

- the investigation is extended to both the cases of PMR and SE (adaptation of vehicle powertrain to reduced mass).

\section{Materials and method}

The study is carried out in two main stages:

- The calculation of use stage FC. Consumption is estimated for various mass-configurations of a certain number of vehicle case studies. Calculation is performed through a car system dynamics simulation modelling. The output of the stage is constituted exclusively by vehicle FC;

- The evaluation of mass-induced FC reduction. Mass-induced FC is estimated starting from the output of the first stage; based on values of FC for different mass-configurations, weight-induced FC is determined through the relationship between consumption and mass.

In the following paragraphs the two stages are illustrated in detail.

\subsection{Calculation of use stage $F C$}

The calculation of use stage FC is performed through a simulation model implemented by the software LMS Imagine. Lab Amesim developed by Siemens (Siemens PLM Software, 2015). The key points of simulation modelling are reported below.

Use stage simulation model. The model estimates the torque at the wheels required to follow the speed profile of the driving cycle by simulating all drivetrain components. The automotive network is subdivided into two sections: drive train (sub-models: engine, clutch, gearbox and vehicle dynamics) and control logic (sub-models: mission profile and ambient data, driver and control unit). Figure 1 reports an overview of the model.

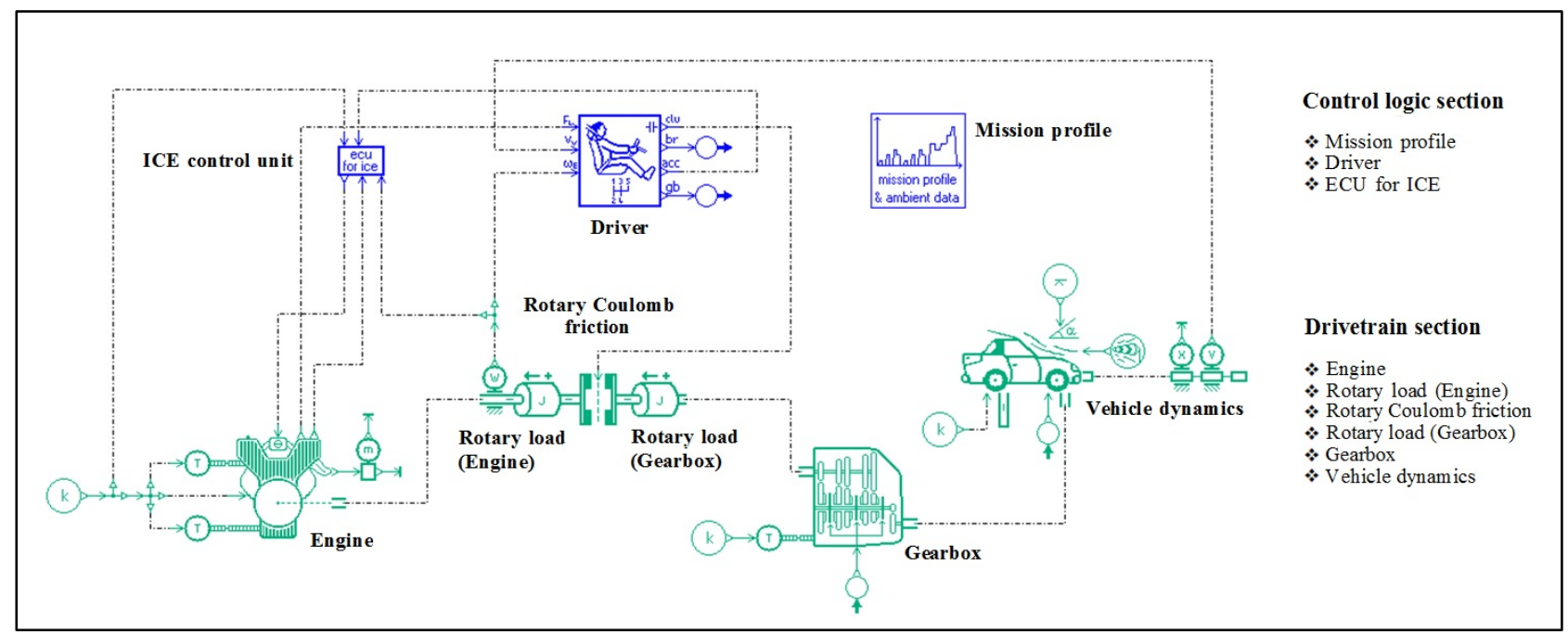

Figure 1. Use stage simulation model

Extension of the analysis. The study investigates GT cars belonging to A/B, C and D classes. These class choices is due to the fact that they constitute the overwhelming majority of cars sold in Europe; similarly, luxury and sport vehicles are excluded from the analysis because they represent niche segments of the market. Assuming only one case study as representative of the entire class would lead to results strongly influenced by technical features (car mass, engine displacement, power and power-to-weight ratio) of the specific model; in order to obtain realistic values of FRV, several case studies have been identified as representative of different classes for a total of 32. For each the technical features refer to a specific 2015 European car model (see Table II in SI appendix); the selection of motorization is performed so that all intended uses within a class are covered, from the entry level to the sporting high performance level. Table 2 reports the min-max range of technical features per vehicle class.

\begin{tabular}{l|c|c|c|c|c}
\cline { 2 - 6 } & $\begin{array}{c}\text { Brake Mean Effective Pressure } \\
{[\text { [bar] }}\end{array}$ & $\begin{array}{c}\text { Displacement } \\
{\left[\mathbf{[ m}^{\mathbf{3}}\right]}\end{array}$ & $\begin{array}{c}\text { Vehicle mass } \\
{[\mathbf{k g}]}\end{array}$ & $\begin{array}{c}\text { Maximum power } \\
{[\mathbf{k W}]}\end{array}$ & $\begin{array}{c}\text { Power-to-mass ratio } \\
{[\mathbf{W} / \mathbf{k g}]}\end{array}$ \\
\hline A/B-class & $18.0-22.5$ & $875-1,395$ & $962-1,155$ & $62.5-110.0$ & $58.1-98.2$ \\
\hline
\end{tabular}




\begin{tabular}{l|l|l|l|l|l}
\hline C-class & $17.5-22.5$ & $999-1,798$ & $1150-1,290$ & $73.5-134.0$ & $60.2-107.5$ \\
\hline D-class & $16.1-22.4$ & $999-1,999$ & $1320-1,489$ & $88.0-176.5$ & $61.5-118.5$ \\
\hline All classes & $16.1-22.5$ & $875-1,999$ & $962-1,489$ & $62.5-176.5$ & $58.1-118.5$ \\
\hline
\end{tabular}

Table 2. Min-max range of vehicle technical features for the considered vehicle classes

Driving cycles. Calculations are performed taking into account four standardized driving cycles: Federal Test Procedure 72 (FTP72) (Barlow et al., 2009), Japan driving Cycle 08 (JC08) (Kuhlwein et al., 2009), NEDC (Barlow et al., 2009) and World Light Test Cycle (WLTC) (Marotta and Tutuianu, 2012). FTP72, JC08 and NEDC are the cycles adopted in the type test approval respectively in the U.S., Japan and Europe while the WLTC is the future European type test approval cycle. The choice to adopt legally binding standardized cycles is dictated by reasons of transparency, consistency and comparability with existing studies.

\subsection{Evaluation of mass-induced FC reduction}

The mass-induced FC reduction is quantified by means of the following relation:

$\Delta F C=F R V * \Delta M$

Where:

$F R V=$ Fuel Reduction Value $[1 / 100 \mathrm{~km} * 100 \mathrm{~kg}]$;

$\triangle F C=$ Fuel Consumption reduction achieved through vehicle mass reduction $[1 / 100 \mathrm{~km}]$;

$\Delta M=$ vehicle Mass reduction $[\mathrm{kg}]$.

The determination of the FRV is based on the outcome of FC obtained by the AMESim simulation model. For each of the vehicle case studies reported in Table II of SI appendix, calculation of consumption is performed for the following five mass-configurations: the reference configuration and 5\%,10\%,15\%,20\% of the lightweight configurations. Once $\mathrm{FC}$ has been determined for all mass-configurations, five points on the diagram "FC - Mass" are known; the FRV is determined as the slope of the regression line of FC in function of mass and is expressed in $1 / 100 \mathrm{~km} * 100 \mathrm{~kg}$.

In the case of PMR consumption of lightweight configurations is calculated maintaining the same vehicle parameters of the reference configuration with the only exception of mass; as the final target is to evaluate the effect of weight on FC, all other specifications remain unaltered.

In the case of SE engine displacement of lightweight configurations is resized so that mass reduction is exclusively used for lowering FC while performance and technological levels remain the same. With respect to performance level, a clear definition has to be adopted. The concept of performance cannot be reduced to one single factor, but it is rather made up of a multitude of different criteria. Usually car magazines base their tests on "acceleration time from 0 to $100 \mathrm{~km} / \mathrm{h}$ ". Rather than acceleration from 0 to a given velocity, elasticity within a certain speed range covers a situation commonly encountered on the road. Accelerating at high velocity is a usual operation for overtaking other vehicles on the highway and represents a risk factor to be minimized by keeping the process as short as possible. The chosen performance criterion is the "elasticity from 80 to $120 \mathrm{~km} / \mathrm{h}$ in the upper gear ratio". With respect to technological level, the following parameters are chosen as representative: Maximum Brake Mean Effective Pressure (BMEP $\max$ ), Stroke-toBore ratio (SBR) and Mean Piston Speed (MPS). The analytical expression of such parameters is reported below:

$B M E P_{\max }=\frac{T_{\max } * 4 \pi}{D}$

$S / B=\frac{\text { Stroke }}{\text { Bore }}$

$M P S=\frac{\text { stroke } * r p m}{30}$

Where:

$B M E P_{\max }=$ maximum Brake Mean Effective Pressure [bar];

$T_{\max }=$ maximum engine Torque $[\mathrm{Nm}]$;

$D=$ engine Displacement [1];

$S / B=$ Stroke-to-Bore ratio [null];

Stroke $=$ engine Stroke $[\mathrm{m}]$;

Bore $=$ engine Bore $[\mathrm{m}]$;

$M P S=$ Mean Piston Speed $[\mathrm{m} / \mathrm{s}]$;

$r p m=$ engine speed $[\mathrm{rpm}]$. 
Figure 2 reports an exemplifying diagram of consumption in function of mass with the relative regression line and FRV coefficient for both the cases of PMR and SE.

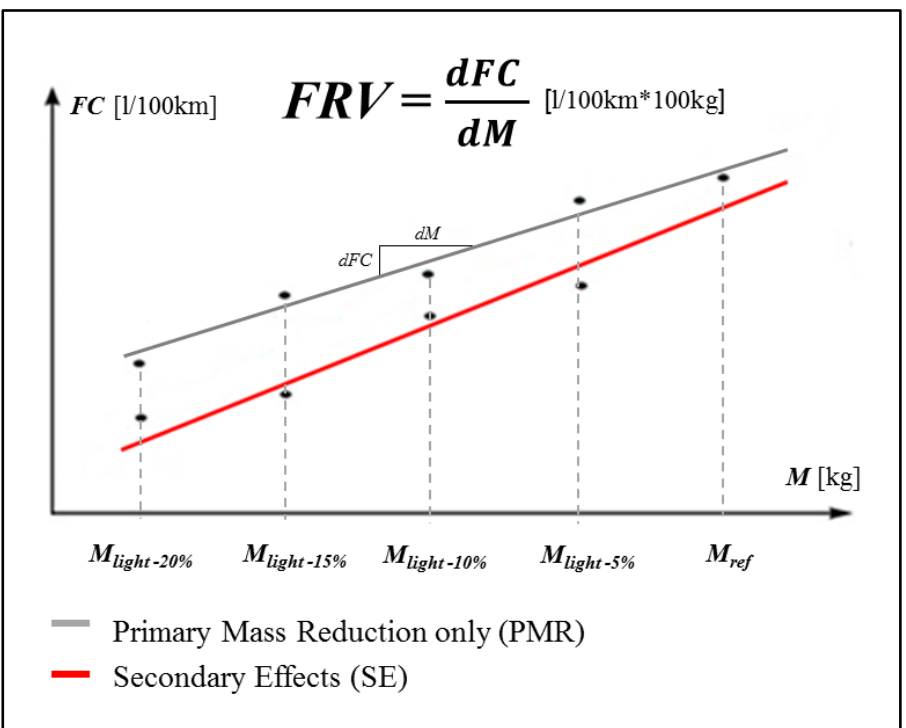

Figure 2. Consumption in function of mass with the relative regression line and FRV coefficient

\section{Results, interpretation and discussion}

Table 3 reports the FRV for all vehicle case studies. Data are presented for

- $\quad$ both PMR $\left(F R V_{P M R}\right)$ and SE $\left(F R V_{S E}\right)$

- $\quad$ each of the considered driving cycles (FRV $\left.V_{F T P 72}, F R V_{J C 08}, F R V_{N E D C}, F R V_{W L T C}\right)$. 


\begin{tabular}{|c|c|c|c|c|c|c|c|c|c|}
\hline \multirow[b]{3}{*}{$\begin{array}{c}\text { Vehicle } \\
\text { Class }\end{array}$} & \multirow[b]{3}{*}{$\begin{array}{l}\text { Case } \\
\text { study }\end{array}$} & \multicolumn{8}{|c|}{$F R V[1 / 100 \mathrm{~km} * 100 \mathrm{~kg}](\mathrm{GT})$} \\
\hline & & \multicolumn{4}{|c|}{ PMR } & \multicolumn{4}{|c|}{ SE } \\
\hline & & 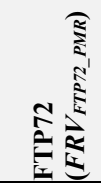 & 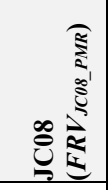 & 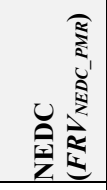 & 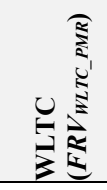 & है & 悹 & 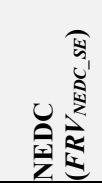 & 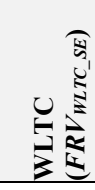 \\
\hline \multirow{10}{*}{$\mathbf{A} / \mathbf{B}$} & 1 & 0.201 & 0.177 & 0.168 & 0.169 & 0.301 & 0.286 & 0.278 & 0.266 \\
\hline & 2 & 0.182 & 0.179 & 0.170 & 0.163 & 0.312 & 0.300 & 0.292 & 0.263 \\
\hline & 3 & 0.166 & 0.171 & 0.166 & 0.163 & 0.345 & 0.329 & 0.321 & 0.294 \\
\hline & 4 & 0.189 & 0.174 & 0.162 & 0.173 & 0.407 & 0.393 & 0.389 & 0.346 \\
\hline & 5 & 0.203 & 0.176 & 0.176 & 0.170 & 0.274 & 0.259 & 0.252 & 0.233 \\
\hline & 6 & 0.193 & 0.178 & 0.176 & 0.169 & 0.304 & 0.287 & 0.274 & 0.267 \\
\hline & 7 & 0.198 & 0.184 & 0.170 & 0.172 & 0.291 & 0.275 & 0.259 & 0.255 \\
\hline & 8 & 0.182 & 0.172 & 0.165 & 0.174 & 0.349 & 0.337 & 0.336 & 0.301 \\
\hline & 9 & 0.177 & 0.180 & 0.172 & 0.161 & 0.317 & 0.314 & 0.293 & 0.263 \\
\hline & 10 & 0.175 & 0.173 & 0.168 & 0.162 & 0.318 & 0.312 & 0.296 & 0.268 \\
\hline \multirow{11}{*}{ C } & 11 & 0.185 & 0.174 & 0.171 & 0.170 & 0.341 & 0.335 & 0.327 & 0.314 \\
\hline & 12 & 0.189 & 0.172 & 0.166 & 0.181 & 0.353 & 0.339 & 0.332 & 0.325 \\
\hline & 13 & 0.177 & 0.177 & 0.162 & 0.167 & 0.315 & 0.303 & 0.293 & 0.273 \\
\hline & 14 & 0.182 & 0.169 & 0.164 & 0.169 & 0.389 & 0.363 & 0.365 & 0.329 \\
\hline & 15 & 0.175 & 0.163 & 0.161 & 0.168 & 0.384 & 0.359 & 0.354 & 0.332 \\
\hline & 16 & 0.187 & 0.172 & 0.168 & 0.174 & 0.342 & 0.328 & 0.324 & 0.310 \\
\hline & 17 & 0.183 & 0.168 & 0.161 & 0.170 & 0.373 & 0.368 & 0.358 & 0.342 \\
\hline & 18 & 0.178 & 0.180 & 0.163 & 0.163 & 0.304 & 0.292 & 0.286 & 0.269 \\
\hline & 19 & 0.179 & 0.181 & 0.169 & 0.163 & 0.298 & 0.287 & 0.282 & 0.265 \\
\hline & 20 & 0.181 & 0.168 & 0.171 & 0.171 & 0.384 & 0.365 & 0.363 & 0.323 \\
\hline & 21 & 0.178 & 0.175 & 0.170 & 0.176 & 0.379 & 0.369 & 0.361 & 0.325 \\
\hline \multirow{11}{*}{ D } & 22 & 0.180 & 0.183 & 0.168 & 0.182 & 0.350 & 0.339 & 0.326 & 0.310 \\
\hline & 23 & 0.237 & 0.200 & 0.191 & 0.184 & 0.477 & 0.420 & 0.409 & 0.354 \\
\hline & 24 & 0.182 & 0.184 & 0.170 & 0.173 & 0.344 & 0.331 & 0.319 & 0.303 \\
\hline & 25 & 0.184 & 0.173 & 0.159 & 0.171 & 0.405 & 0.387 & 0.382 & 0.349 \\
\hline & 26 & 0.182 & 0.184 & 0.172 & 0.180 & 0.375 & 0.352 & 0.338 & 0.314 \\
\hline & 27 & 0.182 & 0.181 & 0.169 & 0.166 & 0.290 & 0.283 & 0.270 & 0.262 \\
\hline & 28 & 0.185 & 0.203 & 0.187 & 0.168 & 0.337 & 0.343 & 0.316 & 0.279 \\
\hline & 29 & 0.210 & 0.188 & 0.174 & 0.183 & 0.462 & 0.434 & 0.429 & 0.345 \\
\hline & 30 & 0.216 & 0.192 & 0.178 & 0.186 & 0.468 & 0.441 & 0.441 & 0.348 \\
\hline & 31 & 0.182 & 0.188 & 0.175 & 0.176 & 0.373 & 0.362 & 0.345 & 0.315 \\
\hline & 32 & 0.206 & 0.191 & 0.182 & 0.187 & 0.436 & 0.406 & 0.388 & 0.352 \\
\hline
\end{tabular}

Table 3. Fuel Reduction Value for all case studies $[1 / 100 \mathrm{~km} * 100 \mathrm{~kg}]$

Table III in SI appendix characterizes the values of FRV in terms of minimum and maximum value, size of range maxmin, arithmetic mean and standard deviation for each of the GT vehicle classes. Figure 3 reports the arithmetic mean of FRV within the class per driving cycle; the black bars identify the maximum range of variation around the arithmetic mean. 


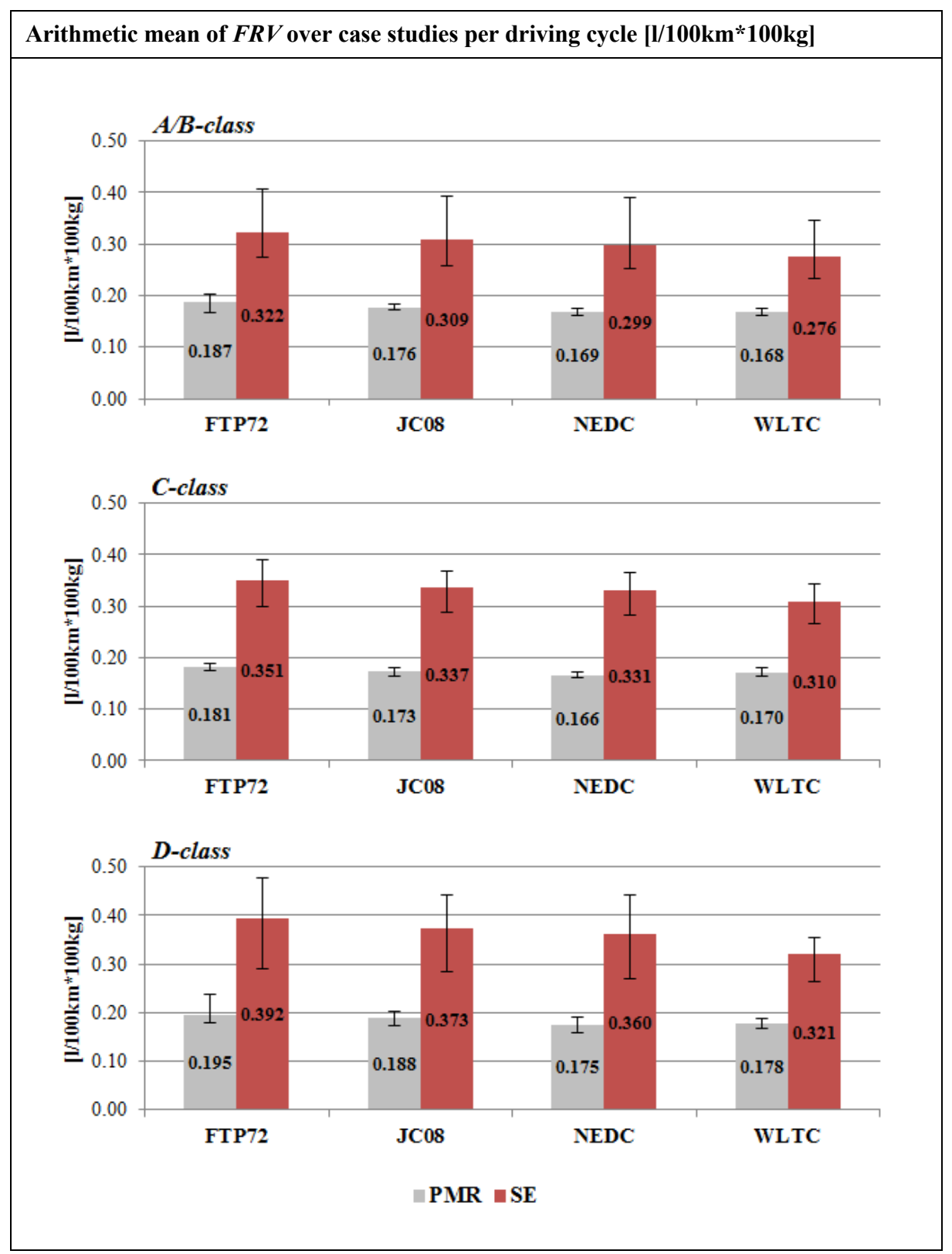

Figure 3. Arithmetic mean of FRV over case studies per driving cycle $[1 / 100 \mathrm{~km} * 100 \mathrm{~kg}]$

Figure 3 and Table III in SI appendix show that for each class $F R V_{S E}$ is characterized by

- higher absolute value

- higher dispersion around the arithmetic mean

with respect to $F R V_{P M R}$.

\subsection{Comparison of FRV with literature sources}

This section compares the FRV values obtained in the study with those from literature. The comparison is performed only with respect to Koffler and Branderburger (2010) and based solely on the FRVSE as it is the only comparable instance in terms of both vehicle case studies (A/B, C and D-classes within the European market), reference driving cycle (NEDC), calculation method (simulation modelling) and applied SE (resizing of engine displacement). Figure 4 shows the comparison of FRV by reporting arithmetic mean and min-max range. 


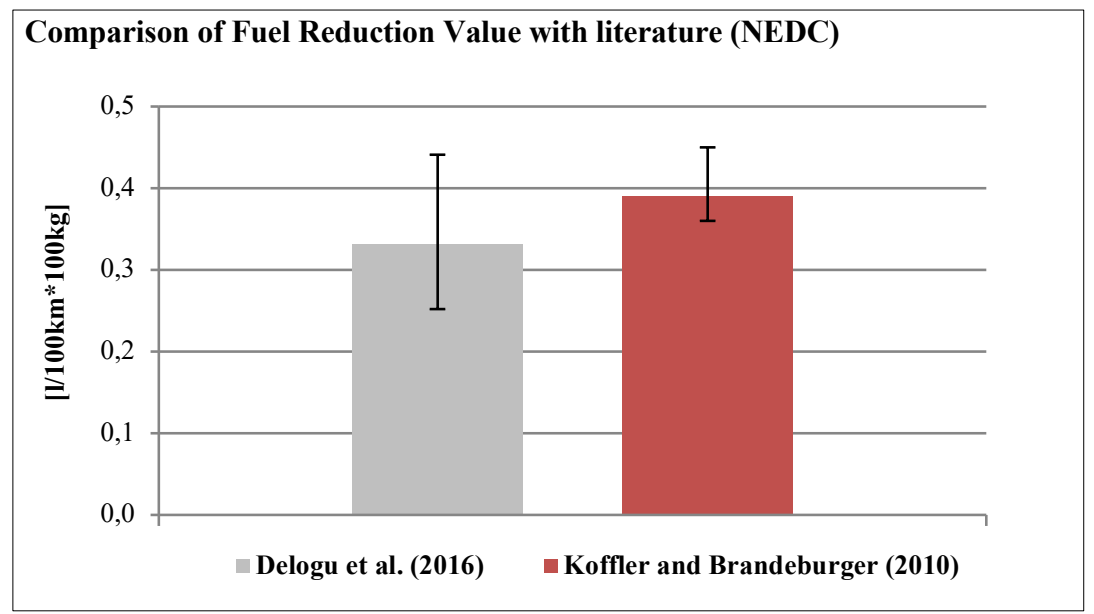

Figure 4. Comparison of Fuel Reduction Value with literature: arithmetic mean and min-max range for FRV

The comparison with Koffler and Brandeburger (2010) shows a moderate reduction of FRV (the mean value is about $15 \%$ lower) and a larger min-max range. The decrease of FRV can mainly be explainable through the lowering of absolute FC triggered by the introduction of the turbocharger and the advancement in engine technological level; as absolute consumption is reduced, also the amount of fuel saving achievable through lightweighting also decreases. The larger range of variability is due to the wider sample of vehicle case studies investigated.

\subsection{Dependence of FRV on driving cycle and vehicle technical features}

The influence of the driving cycle is investigated by analyzing the variation of FRV that occurs passing from one cycle to another; Figure 5 reports the arithmetic mean of FRV over case studies based on the same class.

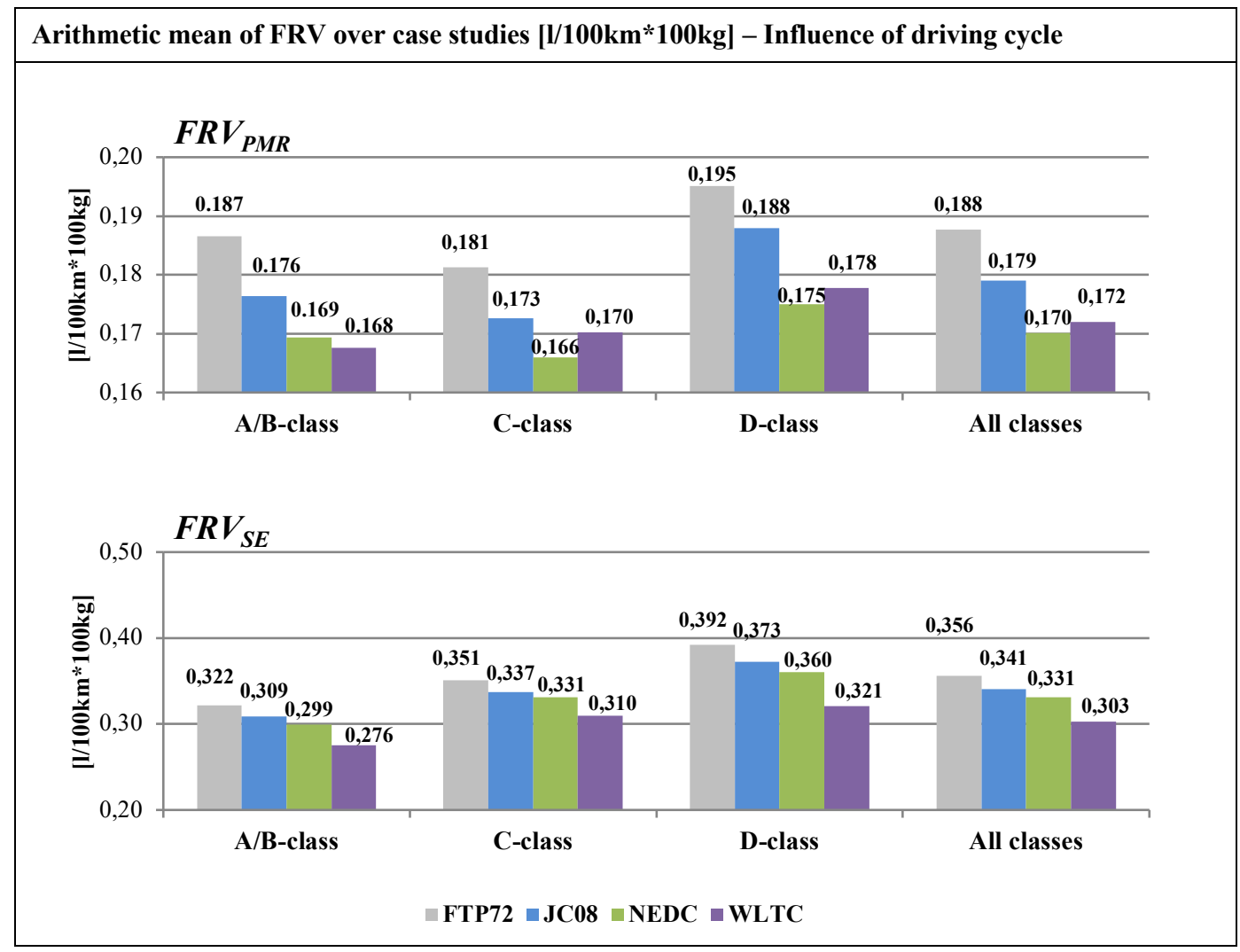

Figure 5. Arithmetic mean of $F R V_{P M R}$ over case studies $[1 / 100 \mathrm{~km} * 100 \mathrm{~kg}]$ : influence of driving cycle

In the case of PMR the highest FRVS refer to FTP72 and JC08 while the lowest refer to NEDC and WLTC. Passing to SE, all classes show the same trend: FTP72 has the highest values followed in succession by JC08, NEDC and WLTC. 
Although the values of FRV depend on technical features of the specific case study, some general observations regarding the influence of the driving cycle can be expressed. The effect on the FRV of the driving cycle is primarily due to the following factors:

- energy consumption per kilometer of mass-dependent resistance forces, given by rolling resistance and acceleration resistance;

- overall vehicle efficiency over the entire cycle.

Considering the first point, the energy consumption per kilometer of mass-dependent resistance factors is higher in the FTP72 and JC08 with respect to NEDC and WLTC. This is a result of the higher mass-dependent resistance forces of these cycles which derive from the more dynamic run. Passing to the second point, the overall vehicle efficiency over the entire cycle results in being higher in NEDC and WLTC. The lower values referring to FTP72 and JC08 are explained by the lower efficiency at which the engine operates in such cycles; this is a result of the fact that the engine works in partialization for a notable share of the total cycle duration due to the frequent speed fluctuations which characterize these cycles. It should also be noted that for PMR the engine base efficiency of lightweight massconfigurations is lower than that of the reference and that it decreases as mass reduction increases; this fact can be explained by the lower engine load required by lightweight mass-configurations in order to follow the velocity profile of the cycle. In the case of SE, the engine base efficiency of lightweight configurations remains substantially unaltered as engine displacement is adjusted on the basis of reduced mass.

Considering the dependence of the FRV on the main vehicle's technical features, the investigated parameters are maximum Brake Mean Effective Pressure (BMEP $\left.P_{\max }\right)$, Mass $(M)$, maximum Power $\left(P_{\max }\right)$ and Power-to-Mass ratio $(P / M)$. The existence of any correlation is investigated through the analysis of regression lines of FRV in function of the cited parameters. Figure 6 reports $F R V_{P M R}$ and $F R V_{S E}$ in function of $B M E P_{\max }, M, P_{\max }$ and $P / M$ with regression lines and corresponding coefficient of determination for the cycle WLTC; Figures I, II and III in SI appendix report the same data respectively for FTP72, JC08 and NEDC. 


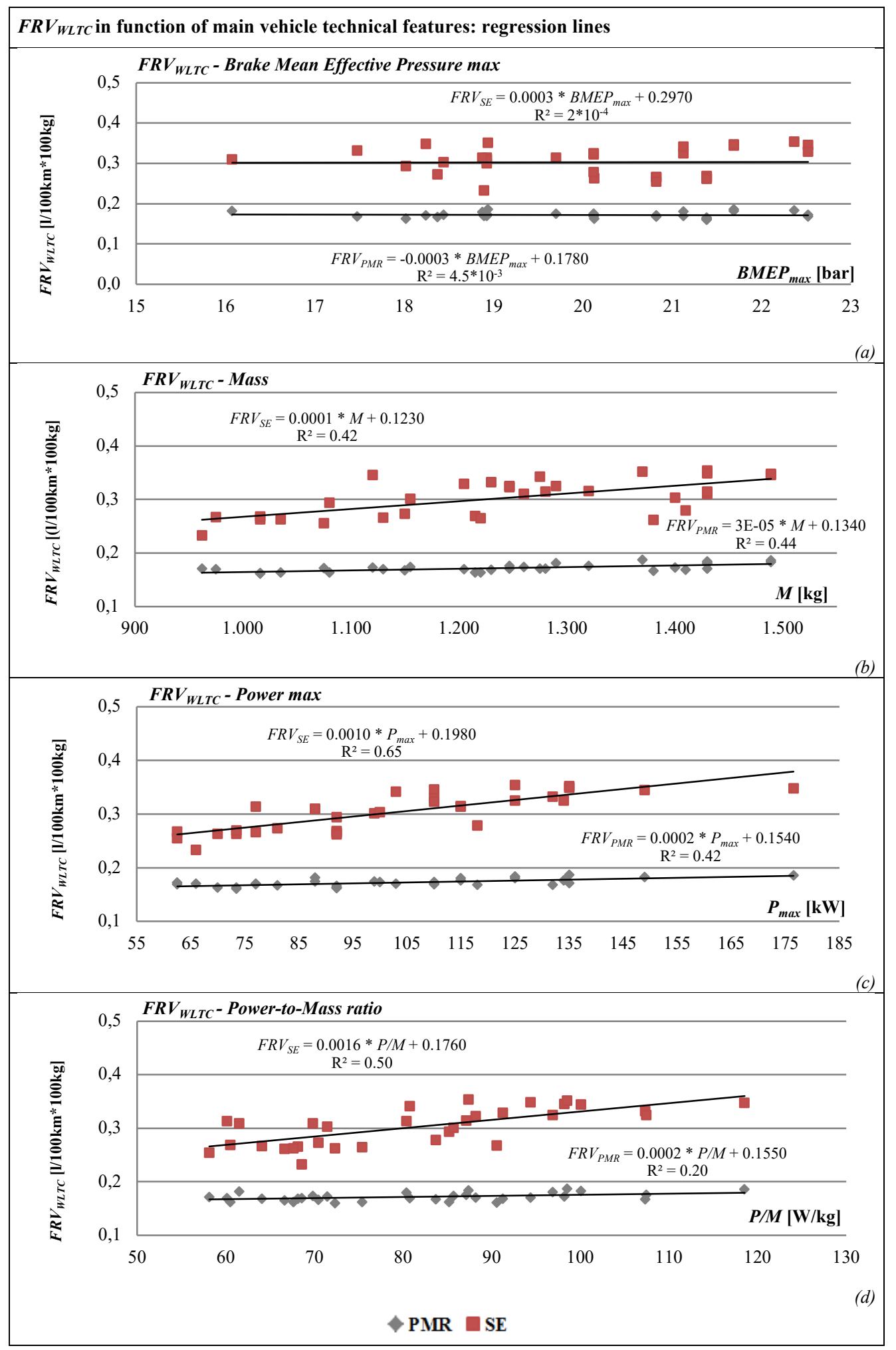

Figure 6. $F R V_{W L T C}$ in function of main vehicle technical features: regression lines. Maximum Brake Mean Effective Pressure (a), vehicle Mass (b), maximum Power (c) and Power-to-Mass ratio (d)

Table 4 quantifies the effectiveness of correlation between FRV and vehicle parameters by reporting $R^{2}$ of regression lines for $F R V_{F T P 72}, F R V_{J C 08}, F R V_{N E D C}$ and $F R V_{W L T C}$. 


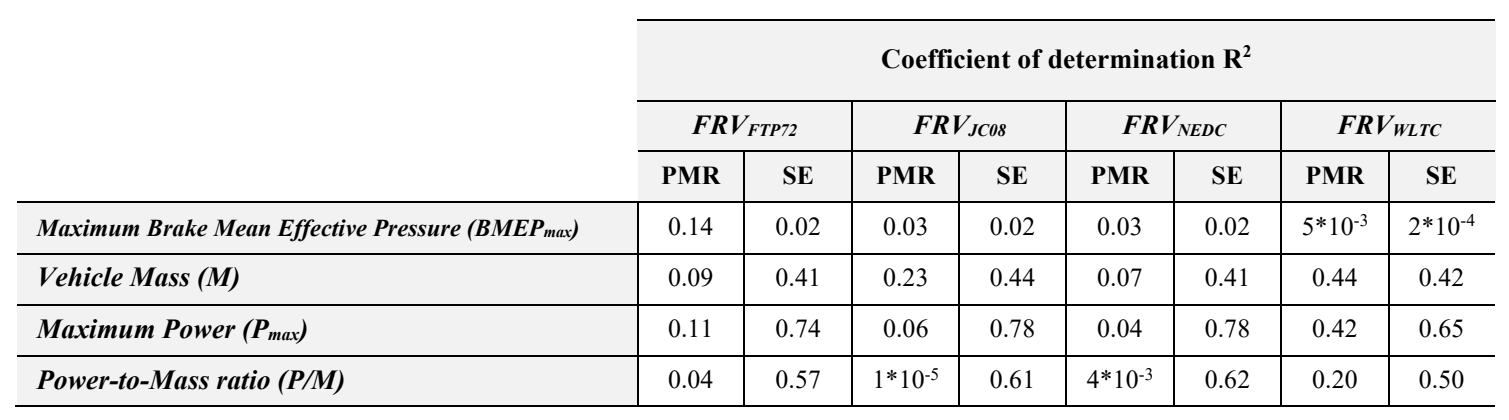

Table 4. Coefficient of determination $\mathrm{R}^{2}$ of regression lines of FRV in function of vehicle technical features

The values of $\mathrm{R}^{2}$ evidence that in case of PMR no correlation between FRV and vehicle technical features exists $\left(\mathrm{R}^{2}\right.$ does not exceed 0.44 ). For $\mathrm{SE}$ the correlation is notably higher and the values of $\mathrm{R}^{2}$ definitely grow:

- the highest correlation is for $P_{\max }\left(\mathrm{R}^{2}\right.$ ranges between a minimum of 0.65 for $F R V_{W L T C}$ and a maximum of 0.78 for $F R V_{J C O 8}$;

- the lowest correlation is for $B M E P_{\max }\left(\mathrm{R}^{2}\right.$ does not exceed 0.02 for all the considered driving cycles);

- intermediate values of $\mathrm{R}^{2}$ refer to $P / M$ and $M$.

\subsection{Vehicle-based modelling of Fuel Reduction Value}

The target of this section is to refine a method which provides an affordable FRV for any generic car model using the FRVs obtained from all the different vehicle case studies. The refined criterion struggles to take into account the variability of the FRV with respect to vehicles' main technical features. The chosen reference parameter for the FRV coefficient is $F R V_{\text {WLTC. }}$. Such a choice is due to the fact that WLTC

- is a worldwide harmonized test cycle developed by member states of the United Nations Economic Commission for Europe, UNECE (including all European countries as well as Japan, USA, China, Russia and India) which is expected to replace the NEDC procedure for European type approval testing within 2017

- represents a realistic driving pattern as it was developed on the basis of current automotive engineering data gathered all around the world and covers disparate driving situations from urban traffic to highways

- represents properly the average driving style of current vehicles and drivers.

Based on the values of $\mathrm{R}^{2}$ reported in Table 4, it has been highlighted that in case of PMR there is a distinct lack of correlation between $F R V_{\text {WLTC }}$ and all the considered parameters. In the case of SE the correlation is notably higher and is maximum for parameter $P_{\max }$. In the light of these considerations:

- the variability of the FRV as a function of the vehicle's main technical features can be taken into account only for the case of SE and it is expressed with a linear relation in function of $P_{\max }$. The chosen function in order to provide FRV $V_{\text {SE }}$ for any generic vehicle model is the regression line of $F R V_{W L T C \_S E}$ (Eq. 7):

$$
F R V_{S E}=0.001 * P_{\max }+0.198
$$

- in the case of PMR the arithmetic mean of FRV WLTC_PMR within the class is assumed.

Table 5 summarizes the chosen approach to quantify the FRV for any generic vehicle model. 


\begin{tabular}{c|c}
\hline \multicolumn{2}{c}{$\boldsymbol{F R V}[\mathbf{1} / \mathbf{1 0 0 k m * 1 0 0 k g ]}$} \\
\hline PMR & \multirow{2}{*}{ SE } \\
\hline$F R V_{P M R}=0.168$ (A/B-class) & \\
\cline { 1 - 1 }$F R V_{P M R}=0.170($ C-class $)$ & \\
\hline$F R V_{P M R}=0.178$ (D-class) & \\
\hline Notes: $P_{\max }$ in $[\mathrm{kW}]$ & \\
\hline
\end{tabular}

Table 5. Criterion for quantifying the FRV coefficient

In the practical application of criterion described above, the following points have to be taken into account:

- the FRV coefficient is determined as the regression line of FC in function of mass for five configurations of the vehicle (the reference configuration and 5\%,10\%,15\%,20\% of the lightweight configurations). As the highest level is $20 \%$, the calculated FRVs have to be considered representative of weight-induced FC saving for mass reductions that do not exceed $20 \%$ of the total. This implies that the refined criterion can be applied to case studies in which weight saving is within $20 \%$;

- the method is applicable exclusively to innovative lightweight solutions that offer advantages in terms of mass reduction only, with all other car efficiency factors being common;

- the criterion is relevant for car models whose technical features are within the range defined by vehicle case studies under consideration (see Table 2).

\subsection{Contribution to Life Cycle Assessment}

This paragraph discusses the application of the FRV coefficient to lightweight automotive LCA evidencing the underlying assumptions, constraints and peculiarities as well the efficacy of the research.

Functional unit. The definition of the functional unit represents a key moment within a LCA, as it heavily influences both the execution of the study and the relevance of final results. Usually lightweight comparative analyses deal with entire vehicles or at least single components; since comparison between the reference and the lightweight solution requires the same basis for evaluation, in both instances the functional unit must to be preserved. In this respect a key consideration regarding the differentiation between PMR and SE has to be made. As mass reduction only results in improved driving features with respect to the reference vehicle, in the case of PMR, the car's performance cannot be included within the functional unit. In the case of SE, the functional unit can include car performance since SE is implemented exclusively in order to lower FC without any improvement in the driving features. Considering that

- $\quad$ lightweight radically influences vehicle performance

- $\quad$ performance is barely a relevant parameter besides being a very influential element for car customers

the adoption of the FRV that takes into account SE appears to be indicated in order to preserve functional equality as much as possible.

Environmental assessment of lightweight. The environmental benefit achievable through lightweighting during the use stage originates from both the fuel cycle (lower amount of fuel to be processed upstream from use) and vehicle operation (reduction of exhaust and evaporative emissions over car life-time). Since a large quota of an ICE car impact is due to the use stage, the potential to lower it by mass reduction is undoubtedly notable. That said, weight saving is not a reliable indicator of improved environmental performance because the adoption of innovative materials often results in increased impacts from the production and EoL stages. This is confirmed by a series of comparative lightweight LCAs (Finkbeiner and Hoffmann, 2006; Zah et al., 2006). For instance Witik et al. (2011) performs the environmental assessment of several suitable lightweight materials (composites and magnesium) as an alternative to steel for a representative automotive component; the study shows that

- impacts from raw materials extraction and production stages of lighter components out-weight the savings in the use stage, resulting in a net increase of the LC environmental burden;

- composite components present higher impacts in the earlier LC stages: production of raw materials (resins and carbon fibers) is strongly energy intensive while manufacturing involves higher energy consumption than steel due to the heat requirements of the curing and forming processes together with longer cycle times. 
In the light of previous considerations it emerges that only a comprehensive assessment of all LC stages permits to assess the environmental implications of lightweighting. In this regard, quantifying as much as possible exactly the amount of mass-induced FC reduction is a key point, as it allows to balance appropriately benefits and disadvantages achievable through weight saving. Here lies the efficacy of the research, that is a vehicle-based modelling of FRV which enables the more accurate determination of the break-even mileage with respect to current LCA applications. To give a qualitative example of this, Figure 7 shows the procedure that should be followed when conducting a comparative lightweight LCA.

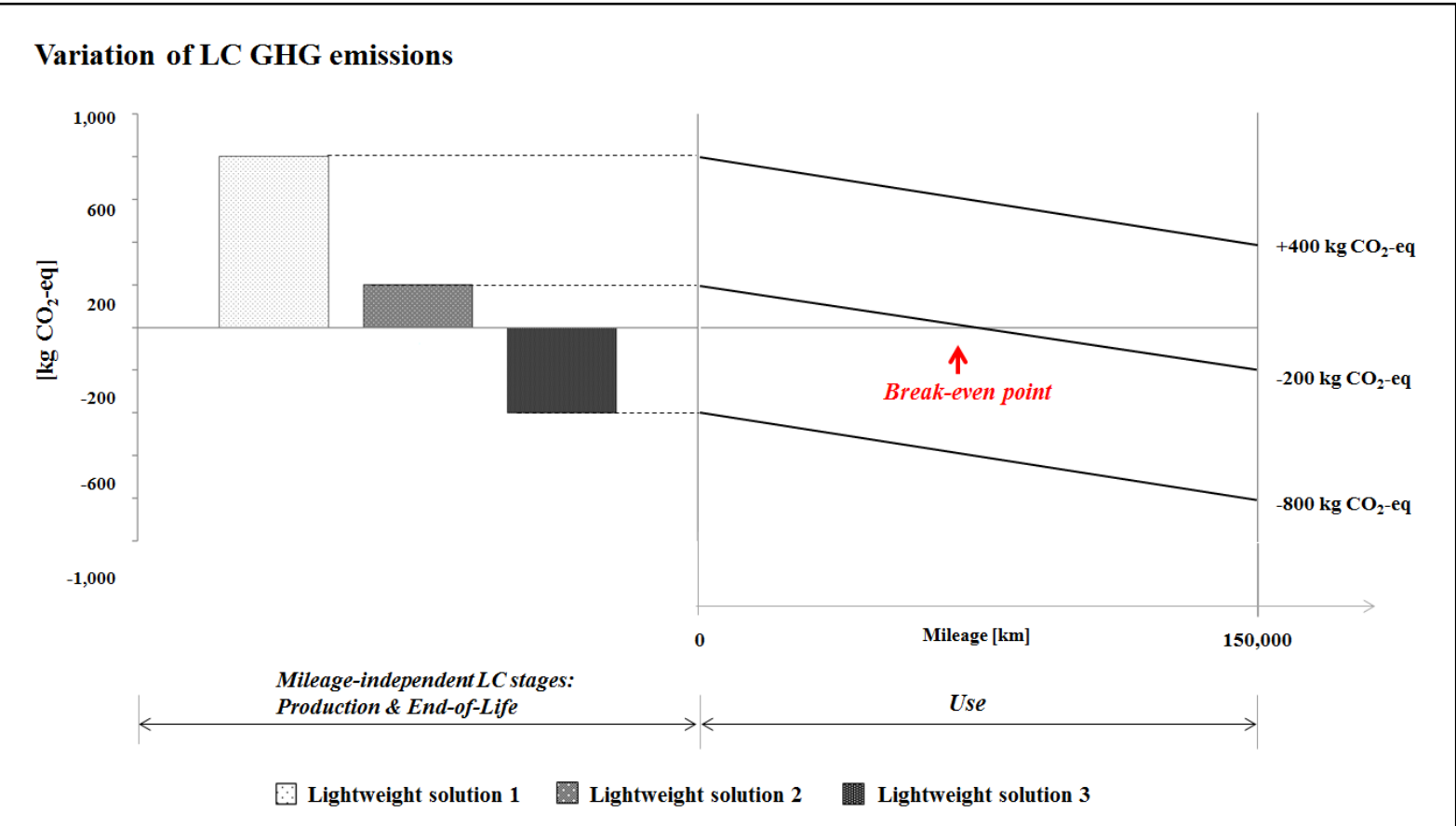

Figure 7. Environmental effect of lightweighting for an ICE automotive asset: variation of LC GHG for three design solutions alternative to the reference one

The diagram considers three different lightweight design solutions which determine the same mass reduction $(\Delta \mathrm{M}=$ $100 \mathrm{~kg}$ ) by reporting the variation of GHG emissions separately for mileage-independent LC stages (production and EoL) and use stage. Since the variation of vehicle weight is equal, the reduction of GHG emissions during use stage is also the same $\left(\Delta \mathrm{GHG}\right.$ emissions $=-400 \mathrm{kgCO}_{2}$-eq); the element distinguishing the three options is the effect on production/EoL, since solutions 1 and 2 present an increase $\left(+800\right.$ and $+200 \mathrm{kgCO}_{2}$-eq respectively) while solution 3 entails a reduction $\left(-400 \mathrm{kgCO}_{2}\right.$-eq). The diagram highlights the strict requirement for the assessment to include all LC stages and to adopt a reasonable estimation of mass-induced FC reduction: against an identical benefit during operation

- $\quad$ solution 1 involves an overall increase of emissions as the beneficial effect of use does not counterbalance the deterioration of mileage-independent stages within the assumed LC mileage $(150,000 \mathrm{~km})$

- $\quad$ solution 2 results in environmental convenience at a break-even point of about 70,000 km, and it involves a $200 \mathrm{kgCO}_{2}$-eq $\mathrm{GHG}$ emissions reduction over LC

- $\quad$ solution 3 leads to the achievement of a large reduction of GHG emissions $\left(-800 \mathrm{kgCO}_{2}\right.$-eq) since all LC stages benefit from the lightweight solution.

Possible future developments. The main development of the research is the estimation of energy reduction value coefficients specific for electric and hybrid vehicles. The extension of the analysis to advanced propulsion technologies would enable to assess lightweighting within different sectors, to compare them and to identify the most profitable one; this would enlarge significantly the application field of the method, making it a valuable tool for taking strategic decisions within the automotive LCA context.

\section{Conclusions}

The study refines an instrument aimed at supporting automotive LCA in the evaluation of environmental benefits achievable through lightweight design solutions. The research proposes a simplified calculation procedure for massinduced FC based on the FRV coefficient functional to modelling the use stage in an LCA perspective. The analysis is targeted at GT cars, since, to date, a systematic analysis for such a propulsion technology is lacking. The FRV is estimated for several vehicle case studies representative of different classes within the 2015 European market and the 
assessment is based on four standardized driving cycles. Starting from all the FRVs obtained for the case studies and driving cycles considered, a criterion is refined which is able to provide an affordable FRV customized to a vehicle's technical features. Such a criterion allows to carefully assess FC reduction by taking into account the value of FRV which is closest to the specific application; the remarkable modularity in FRV estimation enables to examine any of the case studies in all its details, thus improving the level of accuracy of comparative lightweight LCA. The contribution of the research has to be viewed as incorporating energy and environmental issues into the selection process of materials and technologies when developing lightweight design solutions. The possible end-users are practitioners of advanced LCA and original equipment manufacturers that want to assume the environmental concern as a driver of design process. An interesting development of the work is to extend the modelling of mass-induced energy consumption to electric and hybrid vehicles; this would allow to complete the overview on energy and environmental potentialities of lightweighting within the automotive context. 


\section{References}

Aichinger, H.M., 1995. Kraftstoffminderverbrauch durch Gewichtseinsparung an Personenfahrzeugen - Bedeutung des Stahles als Leichtbauwerkstoff, Verein Deutscher Eisenhüttenleute (VDE), Düsseldorf.

An, F., Santini, D., 2004. Mass impacts on fuel economies of conventional versus hybrid electric vehicles, in SAE 2004 World Congress and Exhibition. SAE International, SAE Paper No. 2004-01-0572: Detroit, Michigan, USA.

Alves, C., Ferrao, P.M.C., Silva, A.J., Reis, L.G., Freitas, M., Rodrigues, L.B., 2010. Ecodesign of automotive components making use of jute fiber composites. J. Cleaner Production 2010; 18:313-27.

Barlow, T.J., Latham S., McCrae, I.S., Boulter, P.G., 2009. A reference book of driving cycles for use in the measurement of road vehicle emissions. Copyright TRL.

Baroth, A., Karanam, S., McKay, R., 2012. Life Cycle Assessment of Lightweight Noryl * GTX * Resin Fender and Its Comparison with Steel Fender. 2012 SAE World Congress, Detroit, MI, April 24 - 26; 2012.

Birat, J., Guérin, V., Rocchia, L., Tuchman, M., 2004. Ecodesign of Automobiles based on the environmental properties of body materials. In SAE World Congress and Exhibition; Society of Automotive Engineers: Detroit, MI, March 8-11, 2004.

Casadei, A., Broda, R., 2008. Impact of Vehicle Weight Reduction on Fuel Economy for Various Vehicle Architectures. Ricardo Inc. Report prepared for the Aluminum Association, Inc.

Cheah, L., Evans, C., 2007. Factor of Two: Halving the Fuel Consumption of New U.S. Automobiles by 2035. Massachusetts Institute of Technology.

Das, S., 2000. The Life-Cycle Impacts of Aluminium Body-in-White Automotive Material. Contemporary Al Issues Research Summary.

Dattilo, C.A., Zanchi, L., Del Pero, F., Delogu, M, 2017. Sustainable Design: an Integrated Approach for Lightweighting Components in the Automotive Sector. SDM-2017. 4th International Conference on Sustainable Design and Manufacturing. In press.

Del Pero, F., Delogu, M., Pierini, M., Bonaffini, D., 2015. Life Cycle Assessment of a heavy metro train. Journal of Cleaner Production. Volume 87, 15 January 2015, Pages 787-799.

Delogu, M., Del Pero, F., Romoli, F., Pierini, M., 2015. Life cycle assessment of a plastic air intake manifold. The International Journal of Life Cycle Assessment - October 2015, Volume 20, Issue 10, pp 1429-1443.

Delogu, M., Zanchi, L., Maltese, S., Bonoli, A., Pierini, M., 2016. Environmental and Economic Life Cycle Assessment of a lightweight solution for an automotive component: a comparison between talc-filled and hollow glass microspheres-reinforced polymer composites. Journal of Cleaner Production 139 (2016) 548-560. http://dx.doi.org/10.1016/j.jclepro.2016.08.079 injection molding used for hollow glass microspheres-reinforced polymer composites.

Dhingra, R., Das, S., 2014. Life Cycle energy and environmental evaluation of downsized vs. lightweight material automotive engines. Journal of Cleaner Production, 85 (2014) 347-358.

Du J.D., Han, W.J. , Peng, Y.H., Gu, C.C., 2010. Potential for reducing GHG emissions and energy consumption from implementing the aluminum intensive vehicle fleet in China. Energy 35: 4671-4678 (2010).

Dubreuil, A., Bushi, L., Das, S., Tharumarajah, A., Gong, X., 2010. A comparative Life Cycle Assessment of Magnesium Front End Autoparts. Society of Automotive Engineers (SAE). DOI: 10.4271/2010-01-0275.

Eberle, R., Franze, H.A., 1998. Modelling the Use Phase of Passenger Cars in LCI. Total life cycle conference and exposition. Society of Automotive Engineers (SAE) - SAE Technical Paper, Graz. 
European Commission, 2012. Proposal for a Regulation of the European Parliament and of the Council Amending Regulation (EC) No. 443/2009 to Define the Modalities for Reaching the 2020 Target to Reduce CO2 Emissions from New Passenger Cars European Commission, Brussels (2009).

Finkbeiner, M., Hoffmann, R., 2006. Application of Life Cycle Assessment for the Environmental Certificate of the Mercedes-Benz S-Class (7 pp). Int J Life Cycle Assessment 11, 240-246. doi:10.1065/lca2006.05.248 (2006).

Geyer, 2008. Parametric Assessment of Climate Change Impacts of Automotive Material Substitution. Environmental Science and Technology. doi:10.102/es800314w.

Grujicic, M., Sellappan, V., He, T., Seyr, N., Obieglo, A., Erdmann, M., Holzleitner, J., 2009. Total Life Cycle-Based Materials Selection for Polymer Metal Hybrid Body-in-White Automotive Components. Journal of Materials Engineering and Performance (2009) 18:111-128. DOI: 10.1007/s11665-008-9279-4.

Hakamada, M., Furuta, T., Chino, Y., Chena, Y., Kusuda, H., Mabuchi, M., 2007. Life Cycle Inventory Study on Magnesium Alloy Substitution in Vehicles. Energy 2007, 32, 1352-1360.

Helms, H., Lambrecht, U., Höpfner, U., 2004. Energy savings by light-weighting - Final report. IFEU Institute for Energy and Environmental Research.

Inti, S., Sharma, M., Tandon, V., 2016. An Approach for Performing Life Cycle Impact Assessment of Pavements for Evaluating Alternative Pavement Designs. International Conference on Sustainable Design, Engineering and Construction. Procedia Engineering 145 (2016) 964-971.

Joshi, S.V., Drzal, L.T., Mohanty, A.K., Arora, S., 2004. Are natural fiber composites environmentally superior to glass fiber reinforced composites? Composites: Part A 35 (2004) 371-376.

Kelly, J.C., Sullivan, J.L., Burnham, A., Elgowainy, A., 2015. Impacts of Vehicle Weight Reduction via Material Substitution on Life-Cycle Greenhouse Gas Emissions. Environmental Science and Technology 49, 12535-12542. doi:10.1021/acs.est.5b03192.

Keoleian, G. A., Kar, K., 2003. Elucidating complex design and management tradeoffs through life cycle design: Air intake manifold demonstration project. J. Cleaner Prod. 2003, 11, 61-77.

Keoleian, G. A., Sullivan, J. L., 2012. Materials challenges and opportunities for enhancing the sustainability of automobiles. MRS Bull 2012, 37 (April), 365-372.

Kiefer, B., Deinzer, G., Haagensen, J. Ö., Saur, K., 1998. Life cycle engineering study of automotive structural parts made of steel and magnesium. In Total Life Cycle Conference and Exposition; Society of Automotive Engineers: Graz, Austria, December 1-3,1998.

Kim, H. C., Wallington, T. J., 2013a. Life-cycle energy and greenhouse gas emission benefits of lightweighting in automobiles: Review and harmonization. Environ. Sci. Technol. 2013, 47 (12), 6089-6097.

Kim, H. C., Wallington, T. J., 2013b. Life Cycle Assessment of Vehicle Lightweighting: A Physics-Based Model of Mass-Induced Fuel Consumption. Environ. Sci. Technol. 2013, 47 (24), 14358-14366.

Kim, H. C., Wallington, T. J., Sullivan, J. L., Keoleian, G. A., 2015. Life Cycle Assessment of Vehicle Lightweighting: Novel Mathematical Methods to Estimate Use-Phase Fuel Consumption. Environ. Sci. Technol. 2015, 49 (16), 10209-10216.

Koffler, C., Rodhe-Branderburger, K., 2010. On the calculation of fuel savings through lightweight design in automotive life cycle assessments. Int J Life Cycle Assess 15:128-135. doi:10.1007/s11367-009-0127-z (2010).

Koffler, C., 2013. Life cycle assessment of automotive lightweighting through polymers under US boundary conditions. Int J Life Cycle Assess 19, 538-545. doi:10.1007/s11367-013-0652-7.

Kuhlwein, J., German, J., Baudiradekar, A., 2014. Development of test cycle conversion among worldwide lightduty vehicle $\mathrm{CO} 2$ emission standard. The International Council on Clean Transportation (ICCT). 
La Rosa, A.D., Recca, G., Summerscales, J., Latteri, A., Cozzo, G., Cicala, G., 2014. Bio-based versus traditional polymer composites. A life cycle assessment perspective. Journal of Cleaner Production 74 (2014) 135-144.

Luz, S., Pires, A.C., Ferrao, P.M., 2010. Environmental benefits of substituting talc by sugarcane bagasse fibres as reinforcement in polypropylene composites: eco-design and LCA strategy for automotive components. Resour Conserv Recyc; 54:1135-44 (2010).

Marotta, A., Tutuianu, M., 2012. Europe-centric light duty test cycle and differences with respect to the WLTP cycle. European Commission - Joint Research Centre - Scientific and policy reports.

Mayyas A.T., Qattawi A., Mayyas A.R., Omar M.A., 2012a. Life cycle assessment-based selection for a sustainable lightweight body-in-white design. Energy 39, 412-425 (2012).

Mayyas, A., Qattawi, D., Omar, M., Shan, D., 2012b. Design for sustainability in automotive industry: A comprehensive overiew. Renewable and Sustainable Energy Reviews: 16, 1845-1862 (2012).

Mayyas, A.T., Qattawi, A., Mayyas, A.R., Omar, M., 2013. Quantifiable measures of sustainability: a case study of materials selection for eco-lightweight auto-bodies. Journal of Cleaner Production, Special Volume: Sustainable consumption and production for Asia: Sustainability through green design and practice 40, 177-189.

Mock, P., 2011. Inertia Classes Proposal. WLTP-DTP-LabProcICE-077. Submission to the UNECE GRPE informal subgroup on the development of a worldwide harmonized light vehicles test procedure (WLTP-DTP). The International Council on Clean Transportation (ICCT).

National Research Council (U.S.), 2002. Effectiveness and impact of corporate average fuel economy (CAFE) standards. Washington, D.C.: National Academy Press.

Nemry, F., Leduc, G., Mongelli, I., Uihlein, A., 2008. Environmental Improvement of Passenger Cars, IMPRO-car. Joint Research Center.

Pagerit, S., Sharer, P., Rousseau, A., 2006. Fuel Economy Sensitivity to Vehicle Mass for Advanced Vehicle Powertrains, in SAE 2006 World Congress. SAE International, SAE Paper No. 2006-01-0665: Detroit, Michigan.

Pegoretti, T.S., Mathieux, F., Evrard, D., Brissaud, D., 2014. Use of recycled natural fibres in industrial products: A comparative LCA case study on acoustic components in the Brazilian automotive sector. Resources, Conservation and Recycling 84, 1-14 (2014).

Poulikidou, S., Jerpdal, L., Björklund, A., Åkermo, M., 2016. Environmental performance of self-reinforced composites in automotive applications. Case study on a heavy truck component. Materials and Design 103 (2016) 321-329.

Puri, P., Compston, P., Pantano, V., 2009. Life Cycle assessment of Australian automotive door skins. Int J Life Cycle Assess (2009) 14:420-428. DOI 10.1007/s11367-009-0103-7.

Raugei, M., Morrey, D., Hutchinson, A., Winfield, P., 2015. A coherent life cycle assessment of a range of lightweighting strategies for compact vehicles. Journal of Cleaner Production.

Rechs, M., Pingen, B., Kunde, O., 1995. Fahrzeug- und Motorenkonzepte für das 3-Liter-Auto“, 5. Aachener Kolloquium Fahrzeug- und Motorentechnik, Eurogress Aachen, Oktober.

Redelbach, M., Klotzke, M., Friedrich, H.E., 2012. Impact of lightweight design on energy consumption and cost effectiveness of alternative powertrain concepts. European Vehicle Congress (EEVC), Brussel. (2012).

Ribeiro, C., Ferreira, J.V., Partidàrio, P., 2007. Life Cycle Assessment of a multi-material car component. Int J Life Cycle Assessment 5:336-345 (2007).

Ribeiro, I.; Peças, P.; Silva, A.; Henriques, E. Life Cycle Engineering Methodology Applied to Material Selection, a Fender Case Study. J. Cleaner Prod. 2008, 16, 1887-1899.

Ridge, L., 1997. EUCAR - automotive LCA guidelines - phase 2, Total life cycle conference and exposition. Society of Automotive Engineers (SAE), Graz (1997). 
Rodhe-Branderburger, K., Obernolte, J., 2008. CO2-Potential durch Leichtbau in Pkw, DVM-Tag 2008 Leichtbaustrategein. Deutscher Verband fur Materilforschung und -prufung e.V, Berlin.

Saur, K., Eyerer, P., and Hesselbach, J., 1997. LCA as Decision Making Support in the Automotive R \& D. Society of Automotive Engineers (SAE). SAE Technical Paper 971185, 1997, doi:10.4271/971185.

Schäper, S., Leitermann, W., 1996. Energie, Emissions und Wirkbilanzen von Pkw in aluminium-intensiver und in konventioneller Bauweise sowie Optimierung eines Space-Frame-Karosserie-Konzeptes durch Variation der wesentlichen Fertigungsparameter mittels ganzheitlicher Bilanzierung, Ganzheitliche Betrachtungen im Automobilbau, VDI Bericht 1307, VDI-Verlag, Düsseldorf.

Schäper, S., 1997a. Aluminium-Technologie im Karosseriebau - Audi Space Frame ASF, Entwicklungsmethodik Umwelt, Passive Sicherheit, Audi AG, Ingolstadt.

Schäper, S., 1997b. Recycling of Aluminium Intensive Cars: The Audi A8, International Conference on Car Recycling and Recovery.

Schmidt, W.P., Dahlqvist, E., Finkbeiner, M., Krinke, S., Lazzari, S., Oschmann, D., Pichon, S., Thiel, C., 2004. Life cycle assessment of lightweight and end-of-life scenarios for generic compact class veh icles. Int J Life Cycle Assess 9:405-416 (2004).

Schönemann, M., Schmidt, C., Herrmann, C., Thiede, S., 2016. Multi-level modeling and simulation of manufacturing systems for lightweight automotive components. 48th CIRP Conference on MANUFACTURING SYSTEMS CIRP CMS 2015. Procedia CIRP 41 (2016) 1049-1054.

Shen, D., Phipps, A., Keoleian, G., Messick, R., 1999. Life-cycle assessment of a powertrain structural component: Diecast aluminum vs. hypothetical Thixomolded ${ }^{\circledR}$ magnesium. In SAE International Congress and Exposition; Society of Automotive Engineers, Inc.: Detroit, MI, March 1-4, 1999.

Siemens PLM Software, 2015. Website: http://www.plm.automation.siemens.com/it (accessed: June 2015).

Siskos, P., Capros, P., De Vita, A., 2015. CO2 and energy efficiency car standards in the EU in the context of a decarbonisation strategy: A model-based policy assessment. Energy Policy 84, 22-34.

Simoes, C.L., Figueiredo de Sà, R., Ribeiro, C.J., Bernardo, P., Pontes, A.J., Bernardo, C.A., 2016. Environmental and economic performance of a car component: assessing new materials, processes and designs. Journal of Cleaner Production: 118 (2016) 105-117.

Stichling, J. Life cycle considerations for lightweight automotive design. International Conference: Innovative Developments for Lightweight Vehicle Structures, Wolfsburg, Germany, May 26-27; Volkswagen Group: 2009; pp 209-218.

Stichling, J., Hasenberg, V., 2011. Recycling Lightweight Automobiles. PE International Technical Reports. Available on the internet at: https://www.pe-international.com/ (accessed: 2015).

Stodolsky, F., Vyas, A., Cuenca, R., Gaines, L., 1995. Life-Cycle Energy Savings Potential from Aluminium-Intensive Vehicles. Transportation Technology R\&D Center. Argonne National Laboratory - 9700 South Cass Avenue Argonne, IL 60439.

Sullivan, J. L., Hu, J., 1995. Life cycle energy analysis for automobiles. In Total Life Cycle Conference and Exposition; Society of Automotive Engineers: Vienna, Austria, October 16-19, 1995.

Subic, A., Schiavone, F., 2006. Design-oriented application of LCA to an automotive system. $5^{\text {th }}$ Australian Conference on Life Cycle Assessment. Achieving benefits from managing life cycle impacts. Melbourne, 22-24 November 2006.

Tharumarajah, A., Koltun, P., 2007. Is there an environmental advantage of using magnesium components for lightweighting cars? J. Clean. Prod. 2007, 15, 1007-1013.

Thiel, C., Jenssen, G. B., 2000. Comparative life cycle assessment of aluminium and steel bumper carriers. In Total Life Cycle Conference and Exposition; Society of Automotive Engineers: Detroit, MI, April 26- 28, 2000. 
Tutuianu, M., Marotta, A., Steve, H., Ericsson, E., Haniu, T., Ichikawa, N., Ishii, H., 2013. Development of a Worldwide Worldwide harmonized Light duty driving Test Cycle (WLTC). United Nations Economic Commission for Europe (UNECE) - Working Party on Pollution and Energy group (GRPE).

Vinodh, S., Jayakrishna, K., 2011. Environmental impact minimisation in an automotive component using alternative materials and manufacturing processes. Materials and Design December 2011, Vol. 32, No. 10, pp.5-82-5090 (2011).

Weimar, E., Finkbeiner, M., 2016. Statistical analysis of empirical lifetime mileage data for automotive LCA. Int J Life cycle Assess (2016) 21:215-223. DOI 10.1007/s11367-015-1020-6.

Witik, R.A., Payet, J., Michaud, V., Ludwig, C., Manson, J.A.E., 2011. Assessing the life cycle costs and environmental performance of lightweight materials in automobile applications. Composites: Part A 42, 1694-1709 (2011).

Wohlecker, R., Johannaber, M., Espig, M., 2007. Determination of Weight Elasticity of Fuel Economy for ICE, Hybrid and Fuel Cell Vehicles, in 2007 SAE World Congress. SAE International, SAE Paper No. 2007-01-0343: Detroit, Michigan.

Wötzel, K.; Wirth, R.; Flake, M. Life Cycle Studies on Hemp Fibre Reinforced Components and ABS for Automotive Parts. Die Angewandte Makromolekulare Chemie 1999, 272, 121-127.

Zah, R., Hischier, R., Leao, A.L., Braun, I., 2006. Curauà fibers in the automobile industry - A sustainability assessment. J Cleaner Production; 15:1032-40 (2006).

Zanchi, L., Delogu, M., Ierides, M., Vasiliadis, H., 2016. Life cycle assessment and life cycle costing as supporting tools for EVs lightweight design. Smart Innovation, Systems and Technologies, 52, pp. 335-348. 
SI appendix - Figures

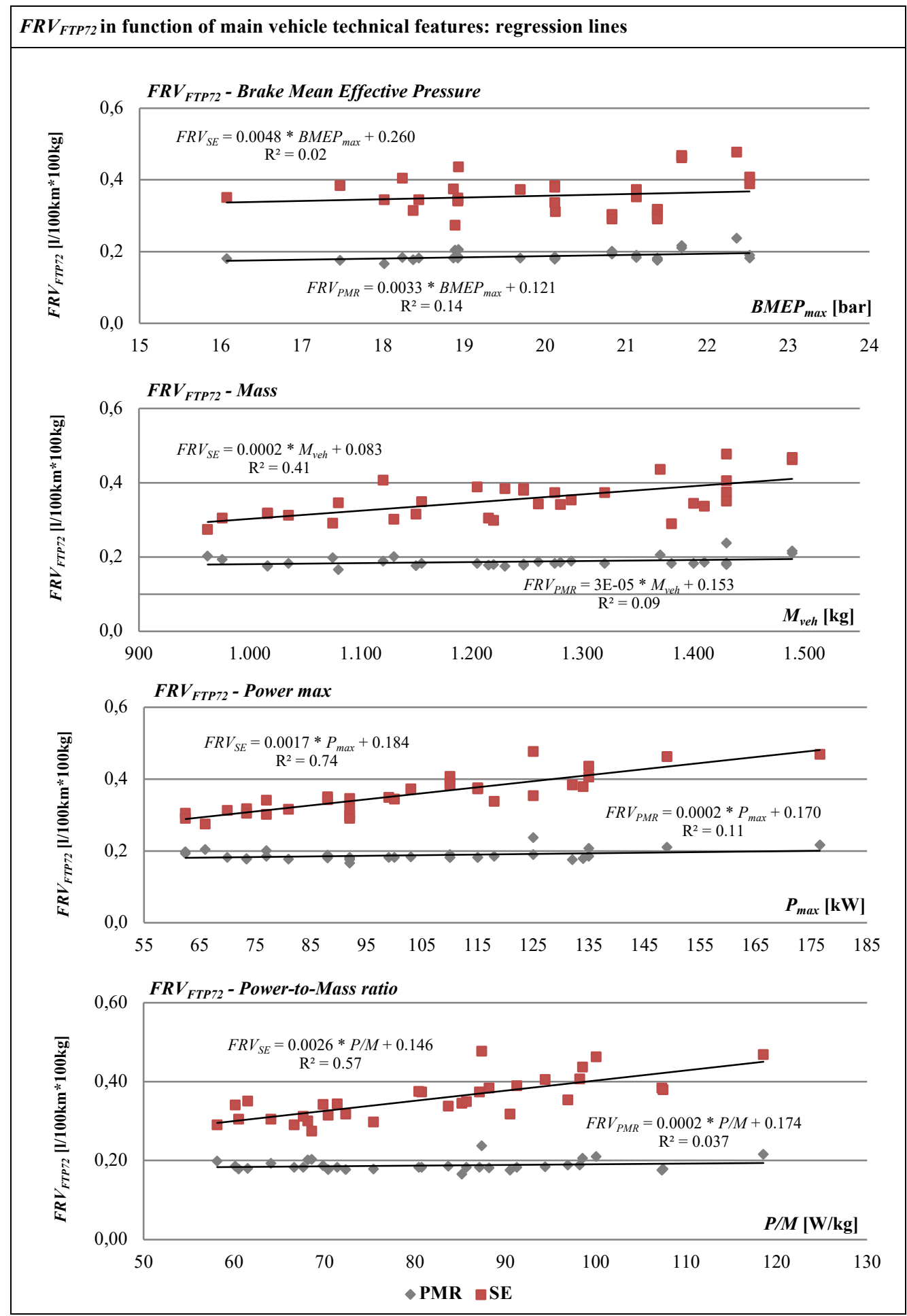

Figure I. FR $V_{F T P 72}$ of all case studies in function of maximum Brake Mean Effective Pressure (BMEP $\max$ ), vehicle mass (Mveh), maximum Power ( $P_{\max }$ ) and Power-to-Mass ratio $(P / M)$ with regression lines and corresponding coefficient of determination $\mathrm{R}^{2}$ 


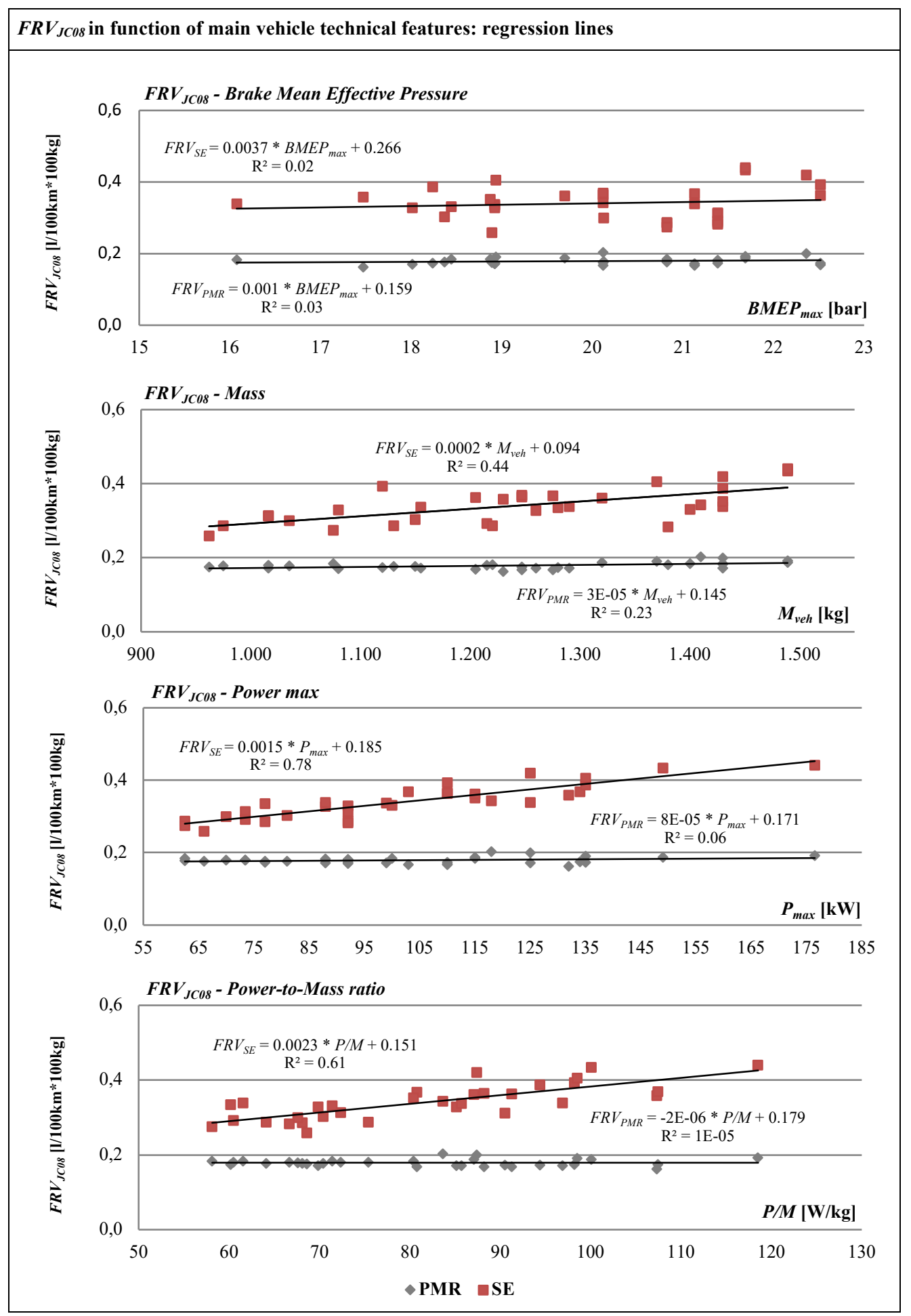

Figure II. FRV $V_{J C 08}$ of all case studies in function of maximum Brake Mean Effective Pressure (BMEP $\max$ ), vehicle mass $\left(M_{\text {veh }}\right)$, maximum Power ( $\left.P_{\max }\right)$ and Power-to-Mass ratio $(P / M)$ with regression lines and corresponding coefficient of determination $\mathrm{R}^{2}$ 


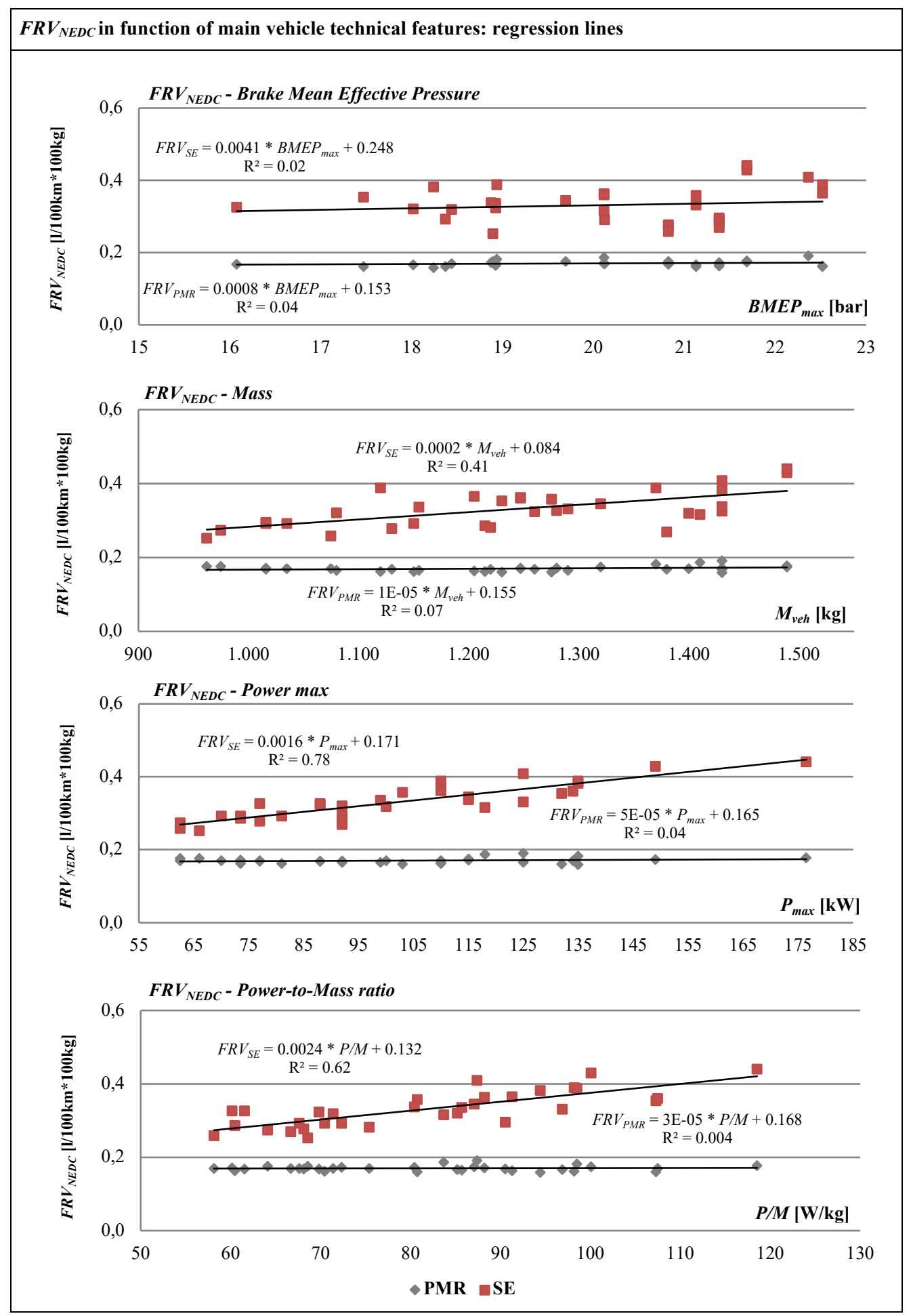

Figure III. FR $V_{N E D C}$ of all case studies in function of maximum Brake Mean Effective Pressure (BMEP ${ }_{\text {max }}$ ), vehicle mass ( $M_{\text {veh }}$ ), maximum Power $\left(P_{\max }\right)$ and Power-to-Mass ratio $(P / M)$ with regression lines and corresponding coefficient of determination $\mathrm{R}^{2}$ 


\section{SI appendix - Tables}

\begin{tabular}{|c|c|c|c|c|}
\hline References & Vehicle size & Includes SE? & $\begin{array}{c}\text { FC reduction due to } \\
100 \mathrm{~kg} \text { mass saving } \\
{[1 / 100 \mathrm{~km} * 100 \mathrm{~kg}]}\end{array}$ & $\begin{array}{l}\text { Percent decrease of } \\
\text { FC due to } 10 \% \\
\text { mass reduction [\%] }\end{array}$ \\
\hline \multirow[b]{2}{*}{ An and Santini, 2004} & C-class (GNA) & Yes & - & 8.0 \\
\hline & $\begin{array}{l}\text { Small Sport Utility Vehicle } \\
\text { (GNA) }\end{array}$ & Yes & - & 7.9 \\
\hline Birat et al., 2004 & Generic GNA car & No & 0.26 & - \\
\hline Cheah, 2007 & Generic GNA car & Yes & - & $1.9-8.2$ \\
\hline Das, 2000 & Generic GNA car & No & - & 5.0 \\
\hline Du et al., 2010 & Not specified & No & 0.48 & - \\
\hline Delogu et al., 2015 & C-class (GNA) & No & 0.15 & - \\
\hline Dubreil et al., 2010 & Generic GNA car & Yes & 0.46 & - \\
\hline Helms et al., 2004 & Not specified & Yes & $0.15-1.00$ & - \\
\hline Keoleain et al., 1998 & Generic GNA car & No & 0.23 & - \\
\hline Keoleian and Kar, 2003 & Not specified & No & 0.20 & - \\
\hline Keoleian and Sullivan, 2012 & Not specified & Yes & 0.37 & - \\
\hline \multirow{2}{*}{ Kiefer et al., 1998} & \multirow{2}{*}{ Generic GNA car } & No & 0.23 & - \\
\hline & & Yes & 0.36 & - \\
\hline National Research Council, U.S., 2002 & C-class (GNA) & Not specified & - & 8.0 \\
\hline Ribeiro et al., 2008 & Not specified & Not specified & 0.6 & - \\
\hline \multirow{4}{*}{ Ridge, 1997} & \multirow{2}{*}{ Generic GNA car } & No & $0.02-0.50$ & - \\
\hline & & Yes & $0.19-0.60$ & - \\
\hline & \multirow{2}{*}{ Generic diesel car } & No & $0.10-0.35$ & - \\
\hline & & Yes & $0.26-0.37$ & - \\
\hline Saur et al., 1997 & Not specified & No & 0.39 & - \\
\hline Schmidt et al., 2004 & Generic GNA car & Not specified & 0.38 & - \\
\hline Shen et al., 1999 & Not specified & No & 0.23 & - \\
\hline Stichling, 2009 & Not specified & Not specified & $0.3-0.6$ & - \\
\hline \multirow{4}{*}{ Stichling and Hasenberg, 2011} & \multirow{2}{*}{ Generic GNA car } & No & 0.15 & - \\
\hline & & Yes & 0.35 & - \\
\hline & \multirow{2}{*}{ Generic DT car } & No & 0.12 & - \\
\hline & & Yes & 0.28 & - \\
\hline Stodolsky et al., 1995 & Generic GNA car & Yes & 0.43 & - \\
\hline \multirow{2}{*}{ Sullivan and $\mathrm{Hu}, 1995$} & \multirow{2}{*}{ Generic GNA car } & No & 0.27 & - \\
\hline & & Yes & 0.40 & - \\
\hline Tharumarajah and Koltun, 2007 & Generic GNA car & No & 0.39 & - \\
\hline Thiel and Jenssen, 2000 & Generic GNA car & No & 0.35 & - \\
\hline Wotzel et al., 1999 & C-class car (GNA) & No & $0.3-0.5$ & - \\
\hline
\end{tabular}

Table I. Values of $F R V$ adopted by some comparative LCAs in literature 


\begin{tabular}{|c|c|c|c|c|c|}
\hline \multicolumn{6}{|c|}{ Reference car models } \\
\hline \multicolumn{2}{|r|}{ A/B-class } & \multicolumn{2}{|r|}{ C-class } & \multicolumn{2}{|r|}{ D-class } \\
\hline Case study & Vehicle model & Case study & Vehicle model & Case study & Vehicle model \\
\hline 1 & A. ROMEO Mito 0.9 TA T $105 \mathrm{cv}$ & 11 & A. ROMEO Giulietta 1.4 TB $105 \mathrm{cv}$ & 22 & AUDI A4 1.8 TFSI $120 \mathrm{cv}$ \\
\hline 2 & AUDI AI 1.0 TFSI $95 \mathrm{cv}$ & 12 & A. ROMEO Giulietta $1.4 \mathrm{~TB} 170 \mathrm{cv}$ & 23 & AUDI A4 1.8 TFSI $170 \mathrm{cv}$ \\
\hline 3 & AUDI A1 1.4 TFSI $125 \mathrm{cv}$ & 13 & AUDI A3 1.2 TFSI $110 \mathrm{cv}$ & 24 & $B M W 318 i 1.5134 \mathrm{cv}$ \\
\hline 4 & AUDI AI 1.4 TFSI $150 \mathrm{cv}$ & 14 & AUDI A3 1.4 TFSI $150 \mathrm{cv}$ & 25 & $B M W 320 i 2.0181 \mathrm{cv}$ \\
\hline 5 & DACIA Sandero 0.9 Tce $90 \mathrm{cv}$ & 15 & AUDI A3 1.8 TFSI $180 \mathrm{cv}$ & 26 & CITROEN C5 1.6 THP $155 \mathrm{cv}$ \\
\hline 6 & FIAT Panda 0.9 TA T $85 \mathrm{cv}$ & 16 & FIAT Bravo 1.4 T-jet $120 \mathrm{cv}$ & 27 & FORD Mondeo 1.0 EB $125 \mathrm{cv}$ \\
\hline 7 & FIAT Punto 0.9 TA T $85 \mathrm{cv}$ & 17 & FIAT Bravo 1.4 T-jet $140 \mathrm{cv}$ & 28 & FORD Mondeo $1.5 \mathrm{~EB} 160 \mathrm{cv}$ \\
\hline 8 & FIAT Punto 1.4 T-jet MA $135 \mathrm{cv}$ & 18 & FORD Focus $1.0 \mathrm{~EB} 100 \mathrm{cv}$ & 29 & FORD Mondeo 2.0 EB $203 \mathrm{cv}$ \\
\hline 9 & FORD Fiesta 1.0 EB $100 \mathrm{cv}$ & 19 & FORD Focus $1.0 \mathrm{~EB} 125 \mathrm{cv}$ & 30 & FORD Mondeo $2.0 \mathrm{~EB} 240 \mathrm{cv}$ \\
\hline 10 & FORD Fiesta 1.0 EB $125 \mathrm{cv}$ & 20 & FORD Focus $1.5 \mathrm{~EB} 150 \mathrm{cv}$ & 31 & MERCEDES C $1801.6154 \mathrm{cv}$ \\
\hline & & 21 & FORD Focus 1.5 EB $182 \mathrm{cv}$ & 32 & MERCEDES C $1802.0181 \mathrm{cv}$ \\
\hline
\end{tabular}

Table II. 2015 European car models chosen as reference for case studies 


\begin{tabular}{|c|c|c|c|c|c|c|c|c|c|c|c|c|c|c|c|c|}
\hline & & \multicolumn{15}{|c|}{ FRV $\left[1 / 100 \mathrm{~km}^{*} 100 \mathrm{~kg}\right]$ - Analysis per vehicle class and driving cycle } \\
\hline & & \multicolumn{5}{|c|}{ A/B-class } & \multicolumn{5}{|c|}{ C-class } & \multicolumn{5}{|c|}{ D-class } \\
\hline & & 吾 & 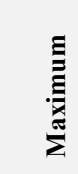 & 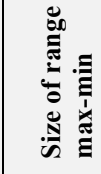 & 营 & 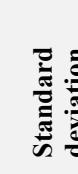 & 吾 & 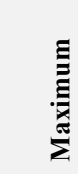 & 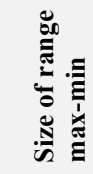 & 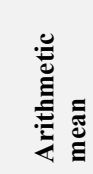 & 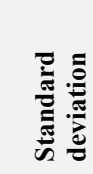 & 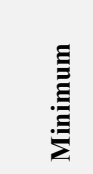 & 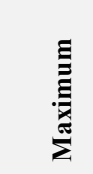 & 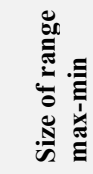 & 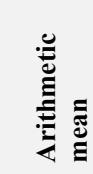 & 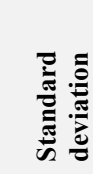 \\
\hline \multirow{4}{*}{ 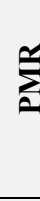 } & $F R V_{F T P 72} P M R$ & 0.166 & 0.203 & \begin{tabular}{|l|l|}
0.037 \\
\end{tabular} & 0.187 & 0.012 & 0.175 & 0.189 & 0.014 & 0.181 & 0.004 & 0.180 & 0.237 & 0.057 & 0.195 & 0.019 \\
\hline & FRV ${ }_{\text {JCO_ } P M R}$ & 0.171 & 0.184 & \begin{tabular}{|l|l|}
0.013 \\
\end{tabular} & 0.176 & 0.004 & 0.163 & 0.181 & 0.018 & 0.173 & 0.005 & 0.173 & 0.203 & 0.030 & 0.188 & 0.009 \\
\hline & $F R V_{N E D C_{-} P M R}$ & 0.162 & 0.176 & 0.014 & 0.169 & 0.005 & 0.161 & 0.171 & 0.010 & 0.166 & 0.004 & 0.159 & 0.191 & 0.032 & 0.175 & 0.009 \\
\hline & FRV $V_{\text {WLTC_PMR }}$ & 0.161 & 0.174 & 0.013 & 0.168 & 0.005 & 0.163 & 0.181 & 0.018 & 0.170 & 0.005 & 0.166 & 0.187 & 0.021 & 0.178 & 0.007 \\
\hline \multirow{4}{*}{ 攽 } & FRV $V_{\text {FTP } 72 \_S E}$ & 0.274 & 0.407 & 0.133 & 0.322 & 0.037 & 0.298 & 0.389 & 0.091 & 0.351 & 0.034 & 0.290 & 0.477 & 0.187 & 0.392 & 0.062 \\
\hline & FRV JCOB_SE & 0.259 & 0.393 & $\mid 0.134$ & 0.309 & 0.038 & 0.287 & 0.369 & 0.082 & 0.337 & 0.031 & 0.283 & 0.441 & 0.158 & 0.373 & 0.049 \\
\hline & $F R V_{N E D C} S E$ & 0.252 & 0.389 & \begin{tabular}{|l|l|}
0.137 \\
\end{tabular} & 0.299 & 0.041 & 0.282 & 0.365 & 0.083 & 0.331 & 0.032 & 0.270 & 0.441 & 0.171 & 0.360 & 0.053 \\
\hline & FR $V_{W L T C}$ SE & 0.233 & 0.346 & \begin{tabular}{|l|l|} 
& 0.113 \\
\end{tabular} & 0.276 & 0.031 & 0.265 & 0.342 & 0.077 & 0.310 & 0.028 & 0.262 & 0.354 & 0.092 & 0.321 & 0.031 \\
\hline
\end{tabular}

Table III. $F R V$ [1/100km*100kg]: analysis per vehicle class and driving cycle in terms of minimum and maximum value, size of range max-min, arithmetic mean and standard deviation 